\title{
Aspectos de la organización económica de las villae de Hispania
}

\author{
Manuel. Villanueva Acuña *
}

\section{RESUMEN:}

En este trabajo a través de una amplia muestra de yacimientos en los que se conocen aspectos de la actividad económica en ellos realizada, se analiza el papel global de la Península lbérica en algunos aspectos de la economía del Imperio, con atencion especial al papel de ciertas áreas como productoras especializadas de productos para la exportación en contraste con otra orientación autosuficiente acentuada en las áreas cuya situación geográfica impide la circulación de bienes a gran escala.

\section{RESUMÉ}

Nous proposons dans ce travail analiser le lieu de la Péninsule Ibérique en quelques aspectes de la vie économique de l'Empire romain. Nous avons choisi un échantillon étendu de établiments ruraux dont nous connaissons des données sur ses activités économiques, pour mettre en relation ses structures productives avec le cadre general ou certaines regions presentent une orientation specialisée pour l'éxportation, tandis que il éxist aussi une autre orientation autarcique plus pesant dans les regions interierures et isolées.

El objeto de este trabajo es hacer una análisis de los datos conocidos acerca de las actividades económicas de las villae de la Península Ibérica

* Universidad de Santiago de Compostela. 
a fin de ilustrar el modo en el que se insertan según las características económicas básicas de las distintas regiones de Hispania. Buscamos así mostrar como la orientación económica de las villae responde a una lógica en la que debe ser tenido en cuenta además su emplazamiento, su ubicación respecto del mar y las arterias económicas fundamentales a través de las que tenía lugar la circulación de bienes. La situación geográfica y la estructura socioeconómica del mundo provincial hispano, en nuestra opinión permite postular dos contextos económicos, que tienen en común el peso de la orientación autosuficiente, y que difieren en el grado de especialización y de producción de excedentes susceptibles de comercialización a través del mercado, la annona u otras formas de circulación de productos.

Al ser sumamente difícil conocer todos los elementos de la economía romana durante el Alto Imperio, para reconstruir en alguna medida las pulsaciones a las que se ve sometida debemos fijar nuestra atención en elementos aíslados que pueden servir de guía para indicarnos las tendencias del conjunto. Así ocurre con fenómenos como la circulación de ciertos productos y su aparición siguiendo ciertas vías en destinos de importación como Roma u otros lugares del imperio, y los signos de prosperidad o decadencia que en los establecimientos rurales o industriales de ciertas áreas podamos detectar, incluso, a ser posible signos indicativos de la situación de las ciudades. No creemos legítimo hablar de una orientación exportadora de la economía penínsular, entendiéndola en un marco como el actual de especialización económica. La unidad que constituía el Imperio Romano no llegaba a crear un espacio económico absolutamente integrado y además el peso de la agricultura y en especial de la autosuficiencia, y el de unas concepciones económicas que, en la Antigüedad, limitaban la autonomía de las decisiones por condicionantes de tipo social y moral, operaban como un freno al libre juego de las actividades económicas.

Pero, con todo, para abordar con rigor los elementos del problema es preciso actuar en una doble perspectiva. Precisar la naturaleza de la economía de las villae hispanas requiere, por una parte, que nos remitamos al contexto económico y las producciones de las distintas áreas peninsulares, que, de manera confusa, conocemos a través de las fuentes clásicas o a través de los datos arqueológicos, y, por otra, que a través de los datos que la exploración de los propios establecimientos y la excavación de las villae peninsulares nos puedan ofrecer, perfilemos lo más exactamente posible la orientación económica de esas explotaciones.

\section{Análisis de los yacimientos:}

En este apartado el objetivo a cumplir es obtener datos de tipo económico que arrojen luz sobre el tipo de actividad agrícola o, en su caso minera, 
industrial o de extracción y transformación de productos del mar, realizados en los establecimientos. Es necesario aclarar que en este proceso, consideraremos de una manera especial actividades de transformación que si bien son de tipo industrial no son la razón de la existencia de la explotación, como la fabricación de ánforas, que en la Bética o en la Tarraconense son parte, en general, de la actividad del establecimiento, a fin de almacenar y exportar los excedentes de la producción, sea del propio establecimiento, o también de otros establecimientos vecinos; o sea, no son la base de una actividad económica autónoma, incluso en los últimos casos citados, a pesar de los problemas que puede plantear la calificación de esas actividades ${ }^{1}$. Nuestra atención se fijará en la interpretación que se puede dar a instalaciones como almacenes, y sus dolia, o restos de instalaciones para la transformación de aceite o vino, en el desgraciadamente escaso panorama penínsular. Ello nos servirá para comprobar las informaciones textuales y para confirmar la vocación de ciertas áreas hacia el cultivo de ciertas cosechas, que con sus excedentes alimentan una circulación de productos hacia otras áreas del imperio. Pero también se tratará de rastrear la importancia que pueda tener la existencia de unos circuitos locales y regionales que pueden tener sus núcleos de articulación en las ciudades y su medio de funcionamiento a través de la red viaria.

\section{Signos de actividad económica en los establecimientos rurales:}

Una serie de indicios en las villae conservadas permiten disponer de elementos que permitan conocer la organización de la vida económica de esos establecimientos. La villa incorporaba dependencias diferenciadas en las que la actividad economica tenía su sede, al margen de la parte señorial o residencial, y esa actividad ha dejado un rastro arqueológico que podemos aspirar a utilizar como guía que nos ayude en la reconstrucción de la base sobre la que se sustentaba su vida. La actividad agraria es la que dio vida a la inmensa mayoría de las villae, pero en algunas otras, actividades como la industria y la minería explican su pujanza y merecen un análisis especial, igual que lo precisan una serie de actividades que solo pueden entenderse como parte de la explotación agraria y que surgen y se desarrollan por la necesidad de exportar los excedentes de esa producción o, simplemente por la más elemental de asegurar la disponibilidad en el

No todos los establecimientos que señalaremos fueron villae con seguridad, pero la relación entre ellos y la economía de las villae es muy profunda. Por ello es legítimo incorporarlos al análisis de la economía de la villa en general. 
marco de la explotación de ciertos bienes que en el mundo antiguo se prefiere manufacturar con los medios propios antes que adquirir en el exterior, y que pueden ir desde materiales de construcción a herramientas y envases.

Para nuestros objetivos son especialmente importantes aquellos establecimientos en los que las dependencias rústicas o industriales fueron descubiertas y suministraron información útil que permita efectuar una reconstrucción fiable del destino que las villae tenían en el plano económico. Es necesario decir que en el plano por el que discurrirá nuestra investigación, los datos no son demasiado abundantes ni reveladores, apreciándose unas diferencias notables de ciertas áreas, como Cataluña y el Valle del Guadalquivir, a las demás, que en parte son debidas al tipo de prospección realizado, poco profundo y sistemático, siendo el conocimiento que tenemos debido a hallazgos casuales en muchos casos, y a excavaciones planeadas en los menos; pero también a una diferente constitución de esas explotaciones agrarias, que en las dos áreas citadas $y$, en cierta medida también en la costa levantina y S.E, presentan una mayor apertura a las corrientes exteriores originadas por la demanda de Roma y que se veía facilitada por su posición geográfica orientada hacia Italia.

Si bien en ciertos establecimientos se refiere el hallazgo de dependencias que se atribuyen a la parte rústica de la villa, el hecho de que no se den a conocer signos claros del destino concreto de esas instalaciones, hace que nos sea poco útil ese tipo de datos, por limitarse a conclusiones verosímiles, pero sin el apoyo de una evidencia material que permita abandonar la generalización ${ }^{2}$. A título orientativo realizamos un examen de los establecimientos conocidos en España en busca de hornos, almacenes, instalaciones de transformación como molinos, prensas, etc., elementos indicativos de actividad económica, por proporcionar un contexto bien analizable -ej.: los almacenes-, o por ser signos altamente significativos -ej.: elementos de molinos, prensas, hornos-. No consideramos en nuestros propósitos los hallazgos de cerámica, que son a veces el signo casi exclusivo de existencia de un establecimiento, pero no suficientemente revelador de su actividad económica.

\footnotetext{
A título de ejemplo citaremos aquí: T. Ortego y Frias: «La villa romana de Santervás del Burgo (Soria)» VI CNA, Oviedo 1959 (Zaragoza 1961), págs. 219-228. "Toda la parte norte la forman robustas medianerias de dependencias complementarias, indispensables en un régimen de vida agrícola y ganadero, que por las condiciones del medio ambiente habían de constituir la base de la economia de esta villa» (pág. 227).
} 
El resultado de este análisis es que el número de establecimientos que aportan este tipo de información es bastante reducido en toda España, pero dentro de esta escasez, en Cataluña y en el Valle del Guadalquivir, como antes adelantamos, los datos son relativamente abundantes, mientras que en los establecimientos del interior, Oeste y Norte de la península, esos datos son muy escasos. Organizaremos el material en función del destino de la instalación y siguiremos un criterio geográfico para enumerar los hallazgos ${ }^{3}$.

\section{HORNOS}

Tenemos testimonios de hornos o indicios de instalaciones de alfareria, en los que se procede fundamentalmente a la cocción de ánforas o ladrillos, en los siguientes puntos de la Península:

a) Cataluña:

Debemos señalar la importancia del primer grupo de establecimientos en los que R. Pascual Guasch demostró la fabricación de un tipo de ánfora vinaria, que se denomina con su nombre: Pascual 1, relacionable con la exportación de vino de Layetania y de Tarraco a Roma ${ }^{4}$. Estos establecimientos son: Caldas de Montbui, Can Cararach, Platja d'Aro, LLavaneres, Turó del Mujal, Alella-Autopista, Reus y Tivissa. Este tipo de ánfora, además de aparecer en otros yacimientos catalanes explorados modernamente, dentro de la región layetana, como Torre Llauder, donde debajo de estratos ya conocidos se descubrió un taller de ánforas Pascual 1 de época augústea ${ }^{5}$, en Malgrat de Mar ${ }^{5}$,

\footnotetext{
3 Evidentemente no hemos pretendido presentar una enumeración completa de los establecimientos conocidos, siempre en aumento, por lo demás, sino que consideramos conveniente utilizar una muestra de yacimientos conocida lo suficientemente extensa para fundamentar las conclusiones que sustentamos.

V. PASCUAL, R.: «Centros de producción y difusión geográfica de un tipo de ánfora». CNA, VIII, 1960 (Zaragoza 1962); PASCUAL, R.: «Algunos aspectos del comercio antiguo según las ánforas». Comunicaciones a la I Reunión de Historia de la economía antigua de la Península lbérica. PLAV 5, Valencia, 1968, p. 67 ss. Excepto Tivissa, situado en el Bajo Ebro y Reus, los establecimientos citados coinciden con los límites supuestos de la regio laietana en época romana. Ver también: A. TCHERNIA: "Les amphores vinaires de Tarraconaise et leur exportation au debut del'Empire». A. Esp. de Arq, 44, 1971, págs. 38-52. Idem: Le vin d'ltalie romaine: Essai d'histoire économique d'après les amphores. Rome, 1986; M. Prevostl: Cronología y Poblament rural a Baetulo. Badalona, 1981.

s PrevostI, M., CLARIANA, J.M.: «El taller de ánforas de Torre Llauder: nuevas aportaciones». Actes $i$ colloqui d'arqueología. El vi a l'antiguitat. Págs. 199-210.

6 V.: F. BuRJachs, J.M. Defaus, M. MiRet y J.M. Solias: «Un centre laietá productor d'envasos vinaris a Malgrat (Maresme)". Acts / colloqui d'arqueologia. El vi a l'antiguitat, págs. 224-228.
} 
en Badalona ${ }^{7}$, pero también en otras áreas próximas, como en LLafranc (Palafrugell) ${ }^{8}$, en la costa de Gerona. Incluso parece haberse reproducido en otros lugares de la península quizás en El Rinconcillo-Algeciras ${ }^{9}$, y también de la Galia Meridional ${ }^{10}$. También dentro de Cataluña, en Vall de María -Arenys de Mar (B 01) ${ }^{11}$ _, en Les Bargotes -(Bigas B 23)-, Can Butinyá -Prevosti, p. 52-3-, Circuitos de motocross -Prevosti. p. 117- LLefiá -Prevosti. p.126-, Can Cabanyes - Prevosti, p. 127, para ánforas, tejas, terra sigillata. V. también Cuyás, 1977, p. 338-, Can Paxau -Prevosti p. 132-, Can Pi i Gibert -Prevosti, p. 140-, Can Canyado -Prevosti, p. 167-, Can Riviere - Prevosti, p. 175, explotación agrícola y con talleres para ánforas-, Can Perxet i Bòbila d'En Jordana -Prevosti, p. 214-, Pont de Tiana -Prevosti, p. 214., Can LLobet en Mataró Gorges B 57-, Mataró-cementerio - Gorges B 59-, San Martí de Sarroca - Gorges B 113- San Vicente de Montalt -Gorges, B 122, horno para ánforas-, Adarró o S. Gervasio en Vilanova y la Geltrù Gorges, B 138, dos hornos de cerámica-, Cala del Forn, Calonge Gorges GE 05-. Recordemos que en los hornos que citamos como fábricas de ánforas del tipo Pascual 1, se fabricaron también Dressel $2-4$, en las que se almacenaba y exportaba vino, y que la fabricación de este último tipo de ánfora, tuvo lugar también en otros puntos

\footnotetext{
7 Puerta, C.; Rodríguez, M.: «Una industria urbana de producció de vi a Baetulo (Badalona)». Actes / Colloqui d'arqueologia romana. El vi a l'antiguitat. págs. 183-8.

${ }^{8}$ Las excavaciones que J. M. ${ }^{a}$ Nolla, J. M. Canes y X. Rocas realizaron en 1980-1 en Llafranc permiten incluir a esta villa entre las fabricantes del tipo de ánfora Pascual 1 . Ver: Nolla, J. M. ${ }^{\text {a; }}$ Canes, J. M. ${ }^{\text {a }}$ y Rocas, X.: "Un forn romà a terrissa a Llafranc (Palafrugell, Empordà). Excavaciós de 1980-1». Ampurias, 44, 1982, pág. 166. Sin embargo, la producción es muy variada, incluyendo ánforas de otros tipos, dolia, cerámica de mesa, ladrillos, tejas, imbrices, etc. «lbidem», pág. 160 ss.

9 Beltrán Lloris, M.: «El comercio del vino antiguo en el valle del Ebro». Actes I colloqui d'arqueologia romana: El vi a l'antiguitat. Economia, producció i comerç al Mediterrani Occidental. (Badalona, 1985), Badalona, 1987, págs. 56-7.

10 Ibidem, pág. 56.

"Los yacimientos que señalamos seguidamente y que estén recogidos en el catálogo de J. C. Gorges: Les villas hispanoromaines, París, 1979, serán citados respetando su criterio de clasificación, indicándolos con las letras iniciales de la provincia (o de los tres sectores en que dividió Portugal: centro, Norte y Sur), y un número. Los que estén recogidos por R. Ponsich, se citan indicando el número de página y el del establecimiento, tal como figuran en sus obras: Implantation rurale antique sur le Bas-Guadalquivir, París, 1974, (Ponsich); Implantation rurale antique sur le Bas-Guadalquivir, II, Paris, 1979, (Ponsich II), e Implanation rurale antique sur le Bas Guadalquivir, III, Madrid, 1987 (Ponsich III), y las que figuran en la obra de Prevosti, M: Cronologia y poblament a l'àrea rural de Baetulo, según su número de página.
} 
citados de Cataluña: S. Vicente de Montalt, Torre Llauder, taller de L. Volteilius en Mataró ${ }^{12}$, Palamós ${ }^{13}$, y en Llafranc (Palafrugell) ${ }^{14}$.

b) Levante

Esta región comenzó a dar en los años 60 restos de instalaciones alfareras, que permiten suponer la existencia de condicionantes parecidos a los que en la costa catalana permitieron a ciertas villae sustentar una economía agraria con cultivos especializados, en los que la industria alfarera sería un complemento imprescindible. Así, debemos señalar varios lugares: en Valencia señalaremos el de Olocau, La Cargadora, Valencia -Gorges V 47, horno de sigillata hispanica (siglo I y comienzos del ॥)-; en Oliva, $R^{a}$ Enguix y $C$. Aranegui, descubrieron un depósito de ánforas vinarias Dressel $2-4$, indicativas de la existencia de un horno, cuya producción ponen en relación con la existencia de viñedos; el vino de Lauro ${ }^{15}$. Este fue el primer descubrimiento importante de alfares, que continuaron con descubrimientos en Sagunto ${ }^{16}$. También hay que señalar la existencia de hallazgos en el área de Denia: Ondara (Partida Vinyals), Denia (La Teulera) y, también en Denia, la villa romana de L'Almadrava ${ }^{17}$.

c) Andalucía.

Al margen de la concentración de hallazgos en la costa catalana, y en especial, Barcelona, solo en otra región nos hallamos ante una densidad comparable de instalaciones; los restos de hornos se concentran en el Bajo Guadalquivir casi exclusivamente, como muestra de manera elocuente la localización conocida de los hallazgos.

12 Véase: Pascual: “Centros de producción...» CNA, VII, 1960, pág. 337, Tchernia, «Las amphores vinaires de Tarraconaise... págs. 60-71, Enguix Alemany, R. y Aranegui Gasco C.: Taller de ánforas de Oliva (Valencia). Valencia, 1977, pág. 28. Nos haremos eco, en último término de algunos hallazgos que incrementan el número de talleres correspondientes a la antigua Layetania, esta vez, en el término de Barcelona: Avinguda Francesc Cambó, Nostra Sra. del Port, y Sitges de l'Estadi de Montjüic, también proquctores de ánforas Pascual 1 y Dressel 2-3. Véase: Granados, J. O., Rovira C.: «Tres nous centres de producció d'àmfores a l'ager de la colònia Barcino". Actes I colloqui d'arqueologia. El vi a l'antiguitat, págs. 128-9.

13 Tremoleda, J.: "La producció del forn de Palamós (Baix Empordá)». Actes / Colloqui d'arqueologia romana. El vi a l'antiguitat, p. 210-7.

14 En las instalaciones mencionadas (v. nota 6), la producción de ánforas del tipo Dressel 24 y Dressel 30 sucede a las Pascual 1. V.: Nolla, Canes y Rocas: «art. cit.», pág. 167.

${ }_{15}$ Vid.: R. ${ }^{\circ}$ EnguIX y C. ARANEGUI: Taller de ánforas romanas de Oliva (Valencia), págs. 43-46.

16 V.: C. ARANEGUI: "Anotaciones sobre las ánforas del nivel de relleno del Grau Vell (Sagunto, Valencia)». Saguntum, 13, P.L.A.V. 1978, p. 308-26; C. ARANEGul, A. MANTILLA: «La producción de ánforas Dr. 2-4 de Sagunto». I colloqui d'arqueologia romana: el vi a l'antiguitat, págs. 100-104.

17 Véase: J. A. GISBERT: «La producció de vi al territori de Dianium durant l'Alt Imperi: El taller d'àmfores de la villa romana de l'Almadrava (Setla-Mirarrosa-Miraflor)". I colloqui d'arqueologia romana: el vi à l'antiguitat, págs. 104-118. 
- Cádiz:

Casa de la Pintada, Puerto de Santa María - Gorges CA 10-; Cerro de los Mártires, Camposoto, San Fernando -Gorges CA 12, villa con taller de alfarero, con muchas ánforas almacenadas y en buen estado y varios hornos casi completos-; El Rinconcillo, Algeciras ${ }^{18}$.

- Sevilla:

En el territorio de Sevilla, al borde del Guadalquivir o no lejos del río, o en afluentes navegables, como la Rivera de Huelva y el Genil, los restos de instalaciones, estudiados fundamentalmente por Ponsich, son numerosos. Estos restos no siempre están asociados a villae, pero creemos que deben ser analizados puesto que el panorama económico en el que juegan su papel, no se puede desligar de la economía agraria de las explotaciones de la región. A su vez creemos que deben ser divididos en dos grupos: 1) Hornos en los que se fabricaron ladrillos, tejas y, frecuentemente, dolia, y, 2) hornos cuya finalidad fue la fabricación de ánforas de aceite $o$, secundariamente, vinarias.

1. Hornos de ladrillos, tegulae, etc:

Cortijo de Campofrío, Salteras -Ponsich p. 48, no 100: villa con horno de ladrillos y tejas-; Cerro de Macareno, La Rinconada -Ponsich p. 53, no 118: hornos de tejas y ladrillos romanos sobre instalaciones anteriores iberopúnicas (desde el siglo V a. C.) -; Cortijo de Majalobas, La Rinconada Ponsich, p. 55, no 123-; Fuente Candón, Alcalá de Guadaira -Gorges SE 01, Ponsich p. 57 no 134-; La Era de Llamas, Guillena -Ponsich p. 78, $\mathrm{n}^{\circ}$ 35: horno cuya actividad parece ser muy tardía: s. IV d. C. e incluso época visigoda-; Piedra Honrada, Guillena - Gorges SE 109, Ponsich p. 80, ํo 45-; Matahijas, Guillena -Ponsich, p. 83, n. 63-; Cortijo de las Cruces, Guillena -Ponsich, p. 83, n. 64, está en una villa-; Olivar de las Rivas o El Moral, Guillena -Ponsich, p. 85, n. 66: villa y horno de ladrillos-; Tierra de Tardón, Alcalá del Río —Ponsich, p. 86, no 72-3: villa y horno de ladrillos-; El Torreón, Burguillos - Gorges SE 22, Ponsich p. 90 , no 101, hornos para ánforas y ladrillos-; Mudapelos, Burguillos —Gorges SE 152, Ponsich p. 93, no111, villa y horno de ladrillos-; Cruz Verde, Brenes -Ponsich p. 108, no 145: hornos de tejas y ladrillos (además de ánforas)-; Cerro de Carma, Alcalá del Río - Ponsich p. 110, ํㅡ 149: villa con hornos de ladrillos y tejas-; Las Pilas, Cantillana - Gorges SE 28,

18 V.: BeltRÁn LloRis, M.: «El comercio del vino antiguo en el valle del Ebro». Actes / colloqui d'arqueologia romana: El vi a l'antiguitat., págs. 56-7. 
Ponsich p. 130, $n^{\circ} 19$, villa con fábrica de ladrillos y tejas-; La Lentiscosa, Villanueva del Río - Gorges SE 182 Ponsich p. 131, n 27: hornos de ladrillos y tejas, formando parte de una villa próxima-; Alcolea del Río Gorges SE 08, Ponsich p. 135, no 41; villa con horno para ladrillos y ánforas-; El Paso, Alcolea del Río - Ponsich p. 145, no 45: hornos de ladrillos (¿y ánforas?)-; El Tejillo, Alcolea del Río -Ponsich p. 145, no 54: complejo en el que se fabrican además de ánforas, ladrillos, tejas, dolia y marmitas-; Los Morales, Cantillana -Ponsich p. 177, no 104, industria de ladrillos, fabricaba para la ciudad de Oducia ladrillos, dolia, tubos y tambores cilíndricos para columnas-; Remolino, Carmona -Ponsich p. 82, ํํ 121 restos de hornos de tejas y ¿ánforas? - Juan Barba, Carmona -Ponsich, p. 183, no 123: Horno de tejas, ladrillos, ánforas, etc. (flor. 100-150 d. C.); Tesoro, Carmona -Ponsich p. 189, no 126: horno de tejas y ladrillos-; Concepción y San Antonio, Carmona -Ponsich p. 190, n 135 , fábrica de ladrillos, tejas y dolia -; Cortijo de Domínguez, Carmona - Gorges SE 34, Ponsich p. 201, no162-3, villa con horno para ladrillos-; Cortijo de las Alberquillas, Lora del Río -Ponsich, p. 208, n 210: villa rústica con horno de ladrillos y tejas-; La Estacada, Lora del Río -Ponsich p. 209, no 216: gran villa rústica con hornos de tejas, ladrillos y ánforas-; Bóveda, Carmona -Ponsich p. 243, no 80: signos de hornos de ladrillos y tejas-; Finca del Farelo, Carmona - Gorges SE 56, Ponsich p. 246, no 98, restos de hornos de ladrillos-; Tierra del Lobo, Carmona - Gorges SE 57, Ponsich p. 248, no 108, restos de hornos-; Chorrillo, Mairena del Alcor Ponsich p. 256, $n^{\circ}$ 153: conjunto habitacional y de talleres con hornos de ladrillos y tejas-; Corroma, Mairena del Alcor —Ponsich p. 257, no 157 ¿horno para ladrillos? -; Cerros de Toruño, Alcalá de Guadaira -Ponsich, p. 268-71, no 237: sede del oppidum Lucurgentium lulii Genius según G. Bonsor; hornos de ladrillos y tejas y cantera de piedra de construcción-; Sta Marina, La Campana —Ponsich, II, p. 26, $n^{\circ}$ 5: indicios de horno de ladrillos (s. IV)-; La Anea, La Campana -Ponsich, II, p. 26, no 8: indicios de hornos de ladrillos y tejas (s. IV)—; El Hornillo, La Campana -Ponsich II, p. 27, $\mathrm{n}^{\circ}$ 14: indicios de hornos de ladrillos (s. IV)-; El Sacristán, La Campana -Ponsich II, p. 29, no 24: horno de ladrillos y tejas-; El Junquillo, La Campana -Ponsich II, p. 31, no 43: horno de ladrillos y tejas (s. IV)-; Alamo Alto, La Campana —Ponsich II, p. 37-9, no 71: villa o quizás portus, con hornos de ladrillos, tejas, dolia y ánforas-; Valbuenas, Ecija —Ponsich II, p. 67, no 139: horno de ladrillos y tejas-; Dehesa Nueva, Ecija —Ponsich II, p. 73, n 179: horno de ladrillos-Antondia, Lora del Río —Ponsich II, p. 82, nº 12-; Alberca, Lora del Río - Ponsich II, p. 82, $\mathrm{n}^{\circ}$ 14: villa con horno de ladrillos-; Tinada de la Vega, Peñaflor Ponsich II, p. 106, no 88: horno de ladrillos-. 


\section{Hornos para ánforas:}

Villar de Brenes (o Puerto el Barco), Brenes - Gorges SE 18, Ponsich p. 99-108 no 143; importante fábrica de ánforas Dressel 20, con varios hornos, que dura entre principios del siglo II y $2^{\mathrm{a}}$ mitad del siguiente-; Cruz Verde, Brenes -Ponsich p. 108, no 145: se fabrican ánforas-; Alcolea del Río - Ponsich p. 135, $n^{\circ}$ 41: villa en la que se fabrican ánforas Dressel 20 y ánforas piriformes para vino-; El Tejillo, Alcolea del Río Ponsich p. 145, no 54: complejo en el que se fabrican ánforas Dressel 20 (flor.: 140-160 d. C.) -; El Castillejo, Alcolea del Río,antigua Arva Ponsich p. 155-168, no 64: centro de producción de ánforas Dressel 20; Guadajoz, Carmona (¿Portus Carmonensis?) —Ponsich p. 180, no 120: hornos para ánforas-; Adelfa, Carmona -Ponsich p. 182, ํo 122: pequeño centro de fabricación de ánforas Dressel 20-; Remolino, Carmona —Ponsich p. 182, no 121: posible fabricación de ánforas-; Juan Barba, Carmona -Ponsich p. 183, no 123- ${ }^{19}$; Villar del Tesoro, Carmona Ponsich p. 186, no 125: fábrica de ánforas a orillas del río Corbones-; Mejía, Carmona -Ponsich p. 190, no 131-2-3: villa con horno para ánforas-; Tostoneras, Lora del Río - Ponsich p. 191, no 136, hornos de ánforas, situados frente a Arva-; Azanaque Castillejo, Lora del Río — Ponsich p. 193, no 145-6: fábrica de ánforas Dressel 20-; El Judío, Lora del Río Ponsich p. 198, no 149: hornos de ánforas-; Pasadas, Lora del Río Ponsich p. 208, $n^{\circ}$ 213: posible horno romano-; La Estacada, Lora del Río - Ponsich p. 209, no 216: gran villa rural en la que hay hornos de ánforas Dressel 20, con varias marcas-; Mochales, Lora del Río - Ponsich II, p. 34, no 67: villa con hornos de ánforas-; Alamo Alto, Lora del Río Ponsich II, p. 37-9, no 71: villa con hornos de ladrillos, tejas y ánforas Dressel 20--; Catria Alta, Lora del Río -Ponsich II, p. 38, no 72: indicios de hornos-La Catria, Lora del Río -Ponsich II, p. 40, n 73: fue estudiado por J. Remesal, es el mayor establecimiento en la misma región, operando al menos entre época Claudia y mediados siglo III (los datos del monte Testaccio en Roma se acaban en ese momento 255-7 d. C.); es un grupo de hornos para ánforas aceiteras Dressel 20, que considera controlado por el fisco o el municipio-- ${ }^{20}$; Cortijo de los Guerras, Lora del Río Ponsich II, p. 40, no 75: hornos de ánforas-; Huerta del Río, Lora del Río -Ponsich II, p. 43, № 79: gran centro de producción de ánforas Dressel 20

${ }_{19}$ Guadajoz, Adelfa y Juan Barba son establecimientos que tienen su período de máximo esplendor en la primera mitad del siglo $\| \mathrm{d}$. C.

${ }_{20}$ V.: J. Remesal Rodríguez: “La economia oleícola bética: nuevas formas de análisis». $A$. Esp. Arq. 1977, págs. 87-143. 
frente a La Catria al otro lado del río Guadalquivir (flor. 90-140 d. C.) -; Haza del Olivo, Lora del Río —Ponsich II, p. 46, no 83: hornos de ánforas-; Cortijo de Manuel Nieto, Lora del Río - Ponsich II, p. 46, no 84: hornos de ánforas Dressel 20-; El Acebuchal, Lora del Río -Ponsich II, p. 49, no 86: horno de ánforas-; La Ramblilla, Lora del Río -Ponsich II, p. 50-1, $n^{\circ}$ 89: horno de ánforas-; Madre Vieja I, Lora del Río -Ponsich p. 51, no 91: horno de ánforas Dr. 20 (datadas en 64-66 d. C. en el M. Testaccio)-; Madre Vieja II -Ponsich II, p. 51, no 92: hornos de ánforas Dr. 20-; Marchente, Lora del Río -Ponsich II, p. 51-4, no 93: hornos de ánforas-; Embalse del Judío, Ecija —Ponsich II, p. 66, no 135 y 136: dos establecimientos de industrias de ánforas Dr. 20-;Tarancón, Ecija Ponsich II, p. 67, no 139: fábrica de ánforas, hornos-; Mallena (o Mayena), Ecija —Ponsich II, p. 83, no 20: villa con hornos de ánforas-; La María, Ecija -Ponsich II, p. 85-6, no 28: centro de producción de ánforas con varios hornos que perdura hasta el s. V-; La María, Ecija -Ponsich II, p. 86, no 29: hornos de ánforas-; Berro I, Ecija -Ponsich II, p. 91, no 56: centro industrial de ánforas ligado probalemente a la villa Berro II-; Berro II -Ponsich II, p. 91, no 57: villa con hornos de ánforas-; La Botica, Peñaflor -Ponsich II, p. 99, n 77: probable centro de fabricación de ánforas-; Peñaflor - Ponsich II, p. 101-2, no 82: la ciudad era núcleo de cruce de caminos entre la zona minera al Norte y la agrícola; hay hornos de fabricación de ánforas-;

- Cordoba

1. Hornos de ladrillos, tejas, etc.

Casas del Picón, Palma del Río -Ponsich II, p. 114, no 120: hornos de ánforas aceiteras -; Isla de la Jurada, Hornachuelos —Ponsich II, p. 139, no 154: villa con hornos que fabrican ladrillos, tejas y ánforas-; villa Cisneros, Hornachuelos -Ponsich II, p. 142-3, no 166: villa que fabrica ladrillos, tejas, dolia, y algunas ánforas-; Dehesa de Arriba, Posadas Ponsich II, p. 149, № 11: importante fábrica de ánforas, tejas, ladrillos y cuencos-; Mingaóbez, Posadas - Ponsich II, p. 155, no 13: 8-10 hornos, en parte de los cuales se fabrican ladrillos, tejas y cuencos-; Haza de los Laticos, Posadas -Ponsich II, p. 160, no 23: Horno de ánforas y ladriIlos-; Casa de Guarda (o Llano), Posadas -Ponsich II, p. 163, no 36 : villa con hornos de ánforas, ladrillos, tejas y dolia (s. IV) -; Estrella, Posadas -Ponsich II, p. 165, no 39: villa con hornos de ánforas y ladrillos (s. IV)-; La Heredad, Bujalance - Ponsich III, p. 39, no 83: horno de tejas-; Cañete de las Torres -Ponsich III, p. 42, no 103: hornos de ladriIlos-; Cerro de la Virgen, Cañete de las Torres -Ponsich III, p. 42-3, no 107: villa o poblado, hornos de tejas-, El Morón, Cañete —Ponsich III, p. 
44, $\mathrm{n}^{\mathrm{o}}$ 117: hornos de tejas-; Veguilla, Villa del Río -Ponsich $p .75, \mathrm{n}^{\circ}$ 28: villa con hornos de tejas-.

2. Hornos de ánforas:

La Sesenta, Palma del Río -Ponsich II, p. 62-4, nº 128: hornos de ánforas-; El Judío, Palma del Río -Ponsich II, p. 65-6, no 133: conjunto de hornos de ánforas Dr. 20-; El Judío -Ponsich II, p. 66, no 134: conjunto de hornos de ánforas-; Huerta de Belén, Palma del Río -Ponsich II, p. 111-2, no 117: alfarería de una villa (fabrica áníoras)-; Casas del Picón, Palma del Río -Ponsich II, p. 114, n 120: hornos de ánforas aceiteras-; Cortijo de Romero, Palma del Río - Ponsich II, p. 116, no 127: villa y alfares (de ánforas) que duran hasta el s. V-; Malpica (Cortijo de), Palma del Río - Ponsich II, p. 123-6, no 140: fábrica de ánforas-; Tierras del Judío, Palma del Río -Ponsich II, p. 127, no 141: hornos de ánforas de una villa-; Villalata, Palma del Río -Ponsich II, p. 128, no 142-; Malpica, Palma del Río -Ponsich II, p. 128, n 143: vasta zona industrial de hornos de ánforas (flor. 130-170 d. C.)-; Isla de la Jurada, Hornachuelos -Ponsich II, p. 139, n 154: villa con hornos que fabrican entre otros productos, ánforas Dr. 20-; Carrascal, Hornachuelos Ponsich II, p. 139, no 156: probable horno de ánforas-; Villa Cisneros, Hornachuelos -Ponsich II, p. 142-3, n 166: villa que fabrica ánforas, ladrillos, dolia, etc.-; Posadas (al Este) -Ponsich II, p. 148, nº 3: villa con hornos de ánforas sin marca (s. IV) -; Dehesa de Arriba, Posadas Ponsich II, p. 149, $\mathrm{n}^{\mathrm{0}}$ 11: importante fábrica de ánforas, tejas, ladrillos, etc-; Mingaóbez, Posadas -Ponsich II, p. 155, no 13: 8-10 hornos, en algunos de los cuales se fabrican ánforas Dr. 20-; Haza de los Laticos, Posadas -Ponsich II, p. 160, nº 23: Horno de ánforas y ladrillos-; Casa de Guarda (o Llano), Posadas -Ponsich II, p. 163, n 36 : villa con hornos de ánforas, ladrillos, etc. (s. IV)-; La Corregidora, Posadas y Almodóvar del Río -Ponsich II, p. 165, n 38 y p. 224, nำ 229: centro de producción de ánforas de aceite que extiende sus restos en el límite de los dos municipios citados-; Estrella, Posadas -Ponsich ll, p. 165, no 39: villa con hornos de ánforas y ladrillos (s. IV) -; La Casilla, Almodóvar del Río Ponsich II, p. 169, nำ 42: horno de ánforas-; Guadiato, Almodóvar del Río -Ponsich, p. 170, $\mathrm{n} \cong$ 44: villa y horno de ánforas-; Villaseca, Almodóvar del Río -Ponsich II, p. 171-2, n 47: centro de producción de ánforas (s. IV)—; Rodriguillo, Almodóvar del Río -Ponsich II, p. 177, $\mathrm{n}^{\circ}$ 54: villa con hornos de ánforas-; Temple, Almodóvar del Río -Ponsich II, p. 182, $\mathrm{n}^{\mathrm{0}} 72$ : hornos de ánforas activo entre fines del s. I y principios del Il d. C.-: Temple o Rodriguillo, Almodóvar del Río - Ponsich II, p. 192, $\mathrm{n}^{\circ}$ 73: hornos de ánforas-; Cortijo del Sotillo, Almodóvar del Río -Ponsich II, p. 200, no 81: villa con hornos de alfareros-; Soto Rey, Fuente Palmera 
—Ponsich II, p. 225, no 233: villa con hornos de ánforas-; Barranco del Picacho, Fuente Palmera -Ponsich II, p. 225, no 234: hornos-; Dehesilla, Fuente Palmera -Ponsich II, p. 228, no 235: tres talleres de ánforas-; La Umbría de Moratalla, Hornachuelos -Ponsich II, p. 228, no 236: hornos de ánforas-; Encinarejo Bajo, Hornachuelos -Ponsich II, p. 231, no 237: hornos de ánforas-;Abramadero (¿Bramadero?), Hornachuelos —Ponsich II, p. 234, no 250: hornos de ánforas-.

\section{- Otros lugares de Andalucía}

Continuando la concentración de establecimientos que acabamos enumerar a lo largo del Guadalquivir, en la provincia de Jaén también se hallan establecimientos en los que existieron hornos, pero, como veremos todos son hornos de ladrillos o tejas, y desaparecen los hornos de ánforas, cosa que ya desde Córdoba es notoria: Así, en Jaén los conocidos son de ladrillos y tejas:

Higuera, Lopera -Ponsich III, p. 50, no 155: hornos de ladrillos-; Valcargado, Lopera -Ponsich III, p. 51, no 163: villa, horno de tejas-; Lopera -Ponsich III, p. 77, no 36: horno de tejas-; La Casilla, Lopera Ponsich III, p. 79, no 52: villa con horno de tejas-; Marqués de la Merced, Marmolejo -Ponsich III, p. 90, no 32: yacimiento con horno de tejas-; Meseta de Nuez Cali, Marmolejo -Ponsich III, p. 91, no 43: horno de tejas y ladrillos en algún luigar próximo-. Un caso especial está constituído por los Villares, Andújar -Ponsich III, p. 85-6, no 70-, porque es un poblado en cuyos hornos se fabrica cerámica sigillata, continuando alfares indígenas anteriores.

En otros lugares de Andalucía, lejos ya de cualquier concentración como la que hemos visto a lo largo del Guadalquivir son muy escasos los hallazgos; así en El Faro, Torrox, Málaga - Gorges MA 13, hornos de ladrillos--, en Puente Carranque, Málaga, Guadarranque (San Roque, Cádiz) y El Rinconcillo de Algeciras, fabricando ánforas Dressel 2-4 ${ }^{21}$, y en Soto de Roma, Dragoleja, Granada - Gorges GR 02, restos de hornosestán los únicos ejemplos.

\section{- Otros lugares de la Península}

Al margen de las áreas mencionadas de Andalucía, Levante y Cataluña, los ejemplos son muy limitados: Hoya de la Sabina, Villanueva

21 Noticia de M. BELTRÁN LloRIs: Cerámica romana: tipología y clasificación. Zaragoza, 1978, que toman R. ENGUIX BELTRÁN LLORIS: «El comercio del vino antiguo en el Valle del Ebro». Actes I colloqui d'arqueologia. El vi a l'antigüitat. pág. 56. 
de la Fuente, Ciudad Real -Gorges CR 04, restos de horno-, son los únicos conocidos en España, mientras que en Portugal:

Póvoa de Meadas, distrito de Portalegre -Gorges PC 22: gran villa o poblado, con un horno de cerámica-; Muge, a orillas del río Tajo -Gorges PC 43: villa con posible horno de cerámica en sus inmediaciones (a $100 \mathrm{~m}$. depósito de fragmentos de ánforas), y exportación por el Tajo-; Vale de Arrancada, Portimao — Gorges PS 40: horno de cal-; Herdade da Barrosinha, Alcácer do Sal —Gorges PS 45: indicios de horno para lámparas y de hornos para ánforas (¿Dressel 14?)-.

\section{- II. INSTALACIONES ACEITERAS Y VINARIAS:}

Otro elemento revelador de la vida económica de las explotaciones rurales son los instrumentos que permiten transformar ciertas producciones, como el trigo en harina o la uva en vino y la oliva en aceite. En este apartado consignaremos los restos de prensas, molinos y muelas utilizados en la fabricación de vino y aceite, que, como veremos, son más abundantes y están más ampliamente distribuidos en las villae de España que los de hornos. Señalemos que M. C. Fernández Castro realizó un inventario de instalaciones aceiteras ${ }^{22}$, aunque nosotros ampliamos a las instalaciones vinarias la investigación. El inventario no puede ser completo por los avances continuos en la exploración arqueológica, pero también porque en ciertos ejemplos no es fácil deducir el destino exacto, fabricación de vino o aceite de las instalaciones, ni es siempre fácil determinar el objeto de los depósitos que aparecen. Así:

- En Cataluña:

Hort del Negre, Badalona -Prevosti, p. 243, piedra que era seguramente la base de una prensa de aceite-, San Cugat, Mataró - Gorges B 53, muela-, Mas Castellar, Els Monjos - Gorges B 62, base de una prensa de vino-, Casalot d'Espuny, Villafranca del Panadés - Gorges B 136, muela-, Els Ametllers, Tossa de Mar - Gorges GE 26; prensa y cuba de aceite-, Can Bosch de Basea, Barcelona ${ }^{23}$, o bien, pertenecientes al ager de Barcino: los de Santa Madrona del Palau; Can Presses del Riu, Ca

${ }^{22}$ V.: M. C. Fernández Castro: «Fábricas de aceite en el campo hispano-romano». Producción y comercio del aceite en la Antigüedad, /l Congreso Internacional. Madrid, 1983, p. 569-599.

23 V.: Olga GIRALT: «El conreu de la vinya a la Hispània romana». Actes / colloqui d'arqueologia. El vi a l'antiguitat. pág. 121. 
l'Espluga, St. Vicenç dels Horts, , S. Boi, Nta Sra de Sales (Viladecans i Gavà), Can Tintorer, Plaça de les Bruixes y Ca la Cordia (Molins de Rei), Pla del Vent (S. Joan Despí), todas ellas situadas en el Bajo Llobregat y de las que se descubrieron instalaciones industriales: prensas y almacenes destinados a la producción de vino ${ }^{24}$.

\section{- En Levante:}

Torassa o Plá Redó, Villarreal —Gorges CS 11, parte de una prensa de aceite-, El Caco, Liria — Gorges V 33, base de prensa-, El Villar o el Puy, Puzol - Gorges V 56, prensa de vino y prensa de aceite, en sendos locales (s. I-II)—, Les Penyetes, Torrent - Gorges V 63, base de una prensa de aceite-, Collado, Villar del Arzobispo -Gorges V 67, piedra de una prensa de aceite o vino-, Pila, Villar del Arzobispo - Gorges, V 68, restos de parte de una prensa de vino-, Casa de les Teules, Elche - Gorges A 04, base de una prensa de vino o aceite-.

- En Murcia:

Llano de Sahués, Abanilla - Gorges MU 01, prensa de aceite-; Villaricos y Fuente Caputa, Mula; Alberca de lo Román, Jumilla, y Cartagena ${ }^{25}$.

\section{- En Andalucía:}

Al igual que con las instalaciones de fabricación de ánforas, la concentración fundamental de instalaciones aceiteras se dá a lo largo del río Guadalquivir y algunos afluentes, siendo en cambio muy escasos los signos de instalaciones vinarias, al contrario, que en la Tarraconense. Así, tenemos en Málaga: Manguarra y S. José, Cartama —Gorges MA $05^{26}{ }^{27}$.

- Sevilla:

Cortijo de Melendo, Lebrija - Gorges SE 122, restos de prensa aceitera-; Hacienda de Marchalamar, Ginés - Gorges SE 105, Ponsich, p. 35,

\footnotetext{
${ }^{24}$ Ver: J.O. Granados, C. ROVIRA: «Tres nous centres de producció d'àmfores a l'ager de la Colonia Barcino». Actes I Colloqui d’arqueologia romana. El vi a l'antiguitat. pág. 127.

25 Estos últimos son tratados por A. Gonzalez Blanco, P. Lillo Carpio, A. Guerrero fúster y S. RAmAllo Asensio: «La industria del aceite en la zona de la actual provincia de Murcia durante la época romana. (Primera aproximación al tema)" en: Producción y comercio del aceite en la Antigüedad: / Congreso, págs. 601-610.

26 Noticia de existencia de instalaciones para la transformación del vino que perduran en época tardía en: O. GIRALT: «El conreu de la vinya a l'Hispània Romana». Actes I colloqui d'arqueologia. El vi a l'antiguitat, pág. 121.

${ }_{27}$ La primera excavación realizada por E. SerRano Ramos y A. DE LuQue Moraño, permitió descubrir las dependencias rústicas y la huella de la existencia de una prensa en una de ellas, que comunicaría con un depósito en la contigua. V.: «La Villa romana de Manguarra y San José en Cártama (Málaga)». En: Segovia y la Arqueología Romana. Barcelona, 1977, pág. 372.
} 
no 34, contrapeso de prensa y ánforas de aceite-; Hacienda de San José, Valencina -Ponsich p. 36, no 44: aceitería-; Hacienda de Tablante, Espartinas - Gorges SE 90, Ponsich p. 40, ํㅜ 59, prensa de aceitunas-; Tanque de Agua, Maribáñez —Gorges SE 149: meta de un gran molino; Sta Cruz, La Rinconada - Gorges SE 156, Ponsich p. 53, 117: muela de molino de aceite, contrapeso de prensa-, Huerta de Torrecilla, Sevilla Gorges SE 172, dos muelas de molino de aceite de arenisca-; Casa de Pelay Correa, Alcalá de Guadaira - Gorges SE 02, Ponsich p. 58, no 138 , aceitería-; Los Olivares, Gerena Ponsich p. 73, no 5: posible aceitería-; Villar de Carrasco, Gerena -Gorges SE 97, Ponsich, p. 73, no 10: aceitería-; Villar del Arroyo de la Casa, Gerena - Gorges SE 99, Ponsich, p. 75, no 19, aceitería-, Casa del Acebuchal, Gerena - Gorges SE 100, Ponsich p. 75, no 20, contrapeso de prensa de aceite-; Arroyo Molinos, Guillena -Ponsich p. 76, no 26: aceitería-; Cortijo del Seroncillo, Gerena -Gorges SE 102, Ponsich p. 77, no 30: probable villa con aceitería (fragmento de contrapeso de prensa de aceite)-; Las Chozas, Alcalá del Rio -Gorges 07, Ponsich p. 88, no 86: aceitería-; Burguillos - Gorges SE 20, Ponsich, p. 89, no 94: depósito de aceite (aceitería)-; El Torreón, Burguillos - Gorges SE 22, Ponsich p. 90, n¹01: villa con aceitería (dos contrapesos de prensa cilíndrica) -; Mudapelos — Gorges SE 152, Ponsich p. $93, \mathrm{n}^{\circ}$ 111: aceitería-; Las Sesenta, Brenes - Gorges SE 17, Ponsich, p. 96, no 132: aceitería, contrapeso de prensa cilíndrico-; Camino de Castillo Blanco, Cantillana -Ponsich p. 128, no6 y p. 128, no 7: posibles aceiterias-; Huerta Alta, Cantillana -Gorges SE 26, Ponsich p. 128, $\mathrm{n}^{\circ}$ 10, aceitería tardía, para Gorges (es empleada una basa de columna para contrapeso de la prensa) - Cortijo de las Torrecillas, Alcolea del Rio Gorges SE 09, Ponsich p. 154,no 59: contrapeso de prensa-; Los Majadales, Lora del Río - Gorges SE 130, Ponsich, p. 168, $n^{\circ} 66$ : contrapeso de prensa aceitera-, La Fábrica, Alcolea del Rio - Gorges SE 10, Ponsich p. 170, ํㅜ 74: aceitería-; Cortijo de San Matías, Alcolea del Río -Ponsich p. 171, no 78: aceitería que funciona hasta el siglo IV d. C.- ; Cortijo de María Luísa, Cantillana - Gorges SE 32, Ponsich, p. 177, n¹05: molinos de aceite, contrapeso de prensa-; Cortijo de Larbona, Tocina Gorges SE 173, Ponsich p. 178, no 113: contrapeso de prensa-; El Judío, Lora del Río - Ponsich p. 198, n 149: aceitería-; Hacienda de Santa Ana, Carmona -Ponsich p. 203, no 177: posible aceitería-; Cortijo de las Alberquillas, Lora del Río - Ponsich p. 208, no 210: villa rústica, aceitería (contrapeso de prensa de aceite) -; La Estacada, Lora del Río Ponsich p. 209, no 216: gran villa rural con aceitería (contrapeso de prensa-; Haza de Habares, Carmona - Gorges SE 41, Fonsich, p. 210, no 220: gran villa romana con aceitería-Trasmuro, Cantillana - Gorges 33, 
Ponsich p. 210, no 222: fondo de cuenca de aceite-; Cortijo del Moscoso, Viso del Alcor -Ponsich p. 241, no 74: gran villa rústica con aceitería-; Huerta de Fabiana, Viso del Alcor —Gorges SE 189, Ponsich p. 241, no 175, dos enormes contrapesos de prensas-; Cortijo de la Esparragosa, Carmona - Gorges SE 49, Ponsich, p. 243, no 81: contrapeso de prensa de aceite-; Cortijo de Sta. Marina - Gorges SE 50, Ponsich p. 243, no 82: contrapeso de prensa de aceite-; La Era, Carmona - Gorges SE 53, Ponsich p. 243, no 91: aceitería-; Hacienda de Buena Cristiana, Carmona - Gorges SE 70, Ponsich 262, no 195, contrapeso de prensa-; Termas de Brenes, Carmona - Gorges SE 75, Ponsich, p. 266, n 223, contrapeso de prensa-; La Tablada, Viso del Alcor —Gorges SE 194, Ponsich p. 278, $n^{\circ}$ 275: contrapeso de prensa-; Las Soleas, Carmona -Ponsich p. 279, no 281: contrapeso cilíndrico de prensa aceitera-; Molino del Francés, Mairena del Alcor —Gorges SE 148, Ponsich p. 280, no 287: aceitería-; Cortijo de San Francisco Javier, La Campana -Ponsich II, p. 28, no 21: restos de la aceitería de una villa-; Masa Verde, La Campana -Ponsich II, p. 29, no 28: molino de aceite-; Cortijo de los Frailes, Carmona Ponsich II, p. 32, no 48: corona de molino de aceite-; Campaniche, Carmona -Ponsich II, p. 32, no 52: molino de aceite-; Cortijo de los Guerras, Lora del Río —Ponsich H, p. 40, no 75: muelas de aceitunas, cuencas-; El Coronel, Carmona -Ponsich II, p. 46, no 80: villa romana y aceitería (s. IV), contrapeso de prensa-; El Coronel -Ponsich II, p. 46, no 81: villa romana y posible aceitería (s. IV)—; Acebuchal, Carmona Ponsich II, p. 49, no 86: contrapeso de prensa-; La Ramblilla, Carmona Ponsich II, p. 50-1, no 89: villa con aceitería-; La Gamera, Carmona Ponsich II, p. 54, no 97: villa con aceitería, muela de aceite-; Marifernández, Fuentes de Andalucía —Ponsich II, p. 59, $n^{\circ}$ 104: fragmento de molino aceitero-; Maluco, Fuentes de Andalucía - Ponsich II, p. 59, $\mathrm{n}^{\circ}$ 108: villa romana con aceitería, moino aceitero-; Jadraque, Fuentes de Andalucía -Ponsich II, p. 60, no 112: villa con aceitería, muela de aceite-; Jadraque - Ponsich p. 60, no 113: villa con aceitería, muela de aceite-; Picate, Ecija -Ponsich II, p. 70, no 159: villa y aceitería-; Cortijo Nuevo, Ecija —Ponsich II, p. 71, no 160: aceitería romana-; Estacas, Ecija -Ponsich II, p. 71, no 161: aceitería romana (s. IV)-; LLeguerisa de Mena, Ecija - Ponsich II, p. 71, no 162: aceitería romana; Alamillo, Ecija —Ponsich II, p. 72, no 168: villa del s. IV, muela de aceite-; San Ignacio del Alamillo, Ecija -Ponsich II, p. 72, no 172: villa y aceitería-; P. K. 471'500, Ecija -Ponsich II, p. 75, nº 194: villa, molino de aceite-; Colmillejo, Lora del Río -Ponsich II, p. 82, $\mathrm{n}^{\circ}$ 13: villa del s. IV, con posible aceitería-; Quinta, Lora del Río - Ponsich II, p. 86, no 32 : villa y aeitería-; Tierras de la Grulla, Lora del Río -Ponsich II, p. 90, no 
49: molino de aceite-; Priorato, Lora del Río —Ponsich II, p. 90, no 51: villa con aceitería, molino de aceite-; Coscoja, Peñaflor - Ponsich II, p. 98, № 73: villa y acetería, molino de aceite-; Escalera, Ecija -Ponsich II, p. 220, no 202: villa romana (s. IV), muela de aceite-; Finca Marta, Ecija -Ponsich II, p. 221, no 206: villa y aceitería, muelas de aceite-

\section{- En Córdoba:}

Alcubilla, Palma del Río -Ponsich II, p. 61, no 117: muela de aceitunas-; Somonte, Palma del Río - Ponsich II, p. 61, no 118: villa y aceitería, molino de aceite--; Injertal de Miravalles, Palma del Río -p. 61, nº 119: aceitería de una villa no descubierta-; Lomas de la Verduga, Palma del Río -Ponsich II, p. 64, no 129: villa con aceitería (s. IV)-; Valbuenas, Palma del Río —Ponsich II, p. 68, no 140: aceitería, molino de aceite-; Pista de Tarancón, Palma del Río -Ponsich II, p. 68, no 143: muela de prensa de aceite-; Cortijo de las Vacas, Palma del Río -Ponsich II, p. 68, no 145: villa y aceitería: contrapeso de prensa-; Cortijo del Instituto, Palma del Río -Ponsich II, p. 109, no 103: muela de aceite-; Llano de Rebelero, Palma del Río -Ponsich II, p. 111, no 115: villa y aceitería (s. IV)-; Remolino, Palma del Río -Ponsich II, p.116, no 128: villa y aceitería (tres muelas de aceite)-; Molino Ali, Palma del Río -Ponsich II, p. 123, no 135: villa y aceitería (s. IV)-; Monte Alto, Hornachuelos —Ponsich II, p. 133, no 144: villa y aceitería, tres molinos de aceite -; El Botijón, Posadas —Ponsich II, p. 158, no 16: contrapeso de prensa-; Haza de los Laticos, Posadas Ponsich II, p. 160, no 23: villa y aceitería, tres contrapesos de prensa y dos muelas-; Vista Alegre, Posadas -Ponsich II, p. 162, $\mathrm{n}^{\circ} 31$ : villa y aceitería-; Zaburda, Posadas —Ponsich II, p. 163, no 32: villa y aceitería-; Casa de Guarda o LLano, Posadas -Ponsich II, p. 163, no 36: villa y aceitería (s. IV)-; Estrella, Posadas -Ponsich II, p. 165, n 39: fragmento de muela de aceite-; Loma de los Almorones, Cuadalcázar —Ponsich II, p. 201, no 86: muela de aceite-; Barbadillo, Guadalcazar -Ponsich II, p. 202, no 91: muela de aceite-; San José, Guadalcázar —Ponsich II, p. 204, no 104: prensa de aceite-; Cortijo de La Orden, Córdoba - Ponsich II, p. 210, no 146: muela de aceite-; Encinajero de los Frailes de S. Jerónimo, Villarrubia - Gorges CO 16, muelas y prensas de gran tamaño-; Fuencubierta, La Carlota -Ponsich II, p. 214, no 159: muela de aceite, aceitería (s. IV)-; Torre de Don Lucas, La Victoria —Ponsich II, p. 219, no 193: muelas de aceite, aceitería (s IV)—; Pelotes, Fuente Palmera -Ponsich II, p. 222, no 214: villa (s. IV), fragmentos de molino de aceite-; Santa Magdalena, Fuente Palmera -Ponsich II, p. 223, $n^{0}$ 221: granja romana y aceitería, muela de aceite-; Soto Rey -Ponsich II, p. 225, no 233: villa y aceitería, molino de aceite-; Abramadero (¿Bramadero?), Hornachuelos -Ponsich II, p. 234, $n^{\circ} 250$ : villa prerromana, después romana, aceitería del siglo IV, 
cuatro molinos de aceite-; Cortijo Nuevo, Hornachuelos -Ponsich II, p. 236, $n^{\circ}$ 254: villa y aceitería (s. IV) -; Barca, El Carpio —Ponsich III, p. 26, no 2: villa con aceitería-; Pernal, El Carpio -Ponsich III, p. 26, no 4: villa con aceitería-; Zaragasilla, Córdoba —Ponsich III, p. 32, no 37: villa, muela de aceite cilíndrica-; Cerro de la Virgen, Cañete de las Torres - Ponsich III, p. 42-3, no 107: fragmento de muela de aceite-; P. K. 353, Montoro Ponsich III, p. 53, no 175: villa, fragmento de molino de aceite-; San Rafael, Montoro -Ponsich III, p. 57, $n^{\circ}$ 188: posible muela de aceite, muela de aceite de tipo fálico-; Cortijo de los Prados, Montoro -Ponsich III, p. 58, no 190: muela de aceite de tipo fálico-; Huerta Mayor, Montoro - Ponsich III, p. 72, no 2: granja con prensa de aceite-; Estación de Montoro - Ponsich III, p. 72, no3: villa con aceitería; prensa-; Casa del Soto, Montoro-Ponsich III, p. 74, no 17: probable villa con su aceitería, molino de aceite-; Pajares (Norte), Montoro -Ponsich III, p. 74, n 22: villa con aceitería-; Pajares, Montoro -Ponsich III, p. 75, no 24: villa con aceitería-; Veguilla, Villa del Río -Ponsich III, p. 75, no 28: villa romana con probable aceitería-.

- En Jaén:

Porcuna (NE) —Ponsich III, p. 46, no 128-; Valcargado, Lopera Ponsich III, p. 51, no 163: villa romana, fragmento de muela de aceite-; Vilavilla, Marmolejo -Ponsich III, p. 88, no 19: contrapeso de prensa de una villa-; Marqués de la Merced, Marmolejo -Ponsich III, p. 89, nº 28: fragmento de molino aceitero-; Garzón, Marmolejo -Ponsich III, p. 91, no 41: fragmento de molino aceitero de una posible villa-; Fuente el Curro Ponsich III, p. 91, no 45: villa con aceitería, contrapeso de prensa-; Ciprés, Andújar -Ponsich III, p. 95, no 67: muela de aceite-; Los Villares, Andújar —Ponsich III, p. 95-6, no 70: poblado con instalaciones aceiteras-; Casilla del Moreno, Villanueva de la Reina -Ponsich III, p. 99, no 89: aceitería que perdura hasta el siglo IV-V-; San Francisco Rosalejo, Villanueva del Río -Ponsich III, p. 104, no 118: villa y aceitería que dura hasta el siglo IV—; Bruñel, Quesada - Gorges J 04, una muela-.

La concentración, tanto de aceiterías como de hornos a lo largo del río Guadalquivir es un hecho que llama la atención en un mapa de distribución de los hallazgos. Entre Sevilla y Córdoba y en función de la navegabilidad del río, se produce esa concentración que da salida a una producción orientada a la exportación.

- Resto de la Península

- Extremadura: Los ejemplos son más escasos; Así:

Mengagil Grande, Medellín - Gorges BA 13: muela de molino de aceite--; Las Lomas, Medellín - Gorges BA 14: muela de granito para molino 
de aceite-; La Cocosa, Badajoz, tiene también instalaciónes aceitera y vinarias.

\section{- Navarra:}

Funes -Gorges NA 10: cuatro salas con prensas y otras cuatro salas para pisar las uvas-; Ermita de San Esteban, Falces - Gorges NA 9, parte rústica excavada, destino agrícola, complejo vinícola del siglo IV, con prensa bien conservada (2 ${ }^{2}$ mitad) - Funes — Gorges NA 10, depósito vinícola, bodega con cuatro salas con prensa y cubas y cuatro aún mayores para pisar las uvas-; Liédena -Gorges NA 12: prensas de vino y aceite correspondientes al nivel más tardío (Liédena II, s. IV) de la villa-.

-La Rioja:

La Morlaca, Villamediana de Iregua; Camino del Pago, Medrano; Turrios, Berceo; Hornos de Moncalvillo ${ }^{28}$; Murillo de Río Leza, y Eras de San Martín, Alfaro ${ }^{29}$.

- Norte de Portugal:

O Fontao, Lavra, distrito de Porto - Gorges PN 12: molino de aceite; Fonte do Milho, Canelas do Douro - Gorges PN 15: establecimiento considerado por sus primeros estudiosos un campamento militar de época de César ${ }^{30}$, lo que Tranoy niega ${ }^{31}$, luego convertido en villa rústica, a partir del siglo III. Molinos y basamento de prensa de aceite y lagares para vino-.

- Centro de Portugal:

Vale de Prazeres, Fundao - Gorges PC 05: contrapeso de prensa-; Beira, Castelo de Vide (Portalegre) -Gorges PC 13: gran villa en zona olivarera, contrapeso de prensa-.

- Sur de Portugal:

Monte do Meio, Beja - Gorges PS 03: gran villa en la que hay una prensa de vino (torcularium) tardía (s. IV) instalada sobre un mosaico anterior, contrapeso y cuba de vino--; Pisoes, Beja -Gorges PS 14: gran villa en

${ }^{28}$ Todos estos yacimientos fueron dados a conocer por M. P. PAscual y FCO. J. MORENo ARRASTIO, «Prensas de aceite romanas en La Rioja». AEA 53, 1980, págs. 199-210.

29 Estos dos últimos ejemplos fueron dados a conocer por: A. GonzÁlez Blanco y A. Hernández Vera: «Más restos de industria oleicola en La Rioja». Producción y comercio del aceite en la antigüedad. II congreso. págs. 611-616.

30 V.: F. Russell Cortez: "Actividades arqueológicas de Portugal en 1948». A. Esp. Arq., XXII, 1949, págs. 400-412. Gorges, «loc. cit.» acepta esta interpretación.

31 V.: Tranor, A.: La Galice Romaine, París, 1981, págs. 238-9. 
cuya parte rústica hay instalación aceitera (hallazgo de grandes piezas de prensas de aceite y una asa de ánfora Dressel 20)—; Quintos, Beja Gorges PS 15: torcularium de una villa; la prensa se dos cellae cuyo líquido (aceite o vino) se recogía en una canalización de plomo-; $N^{a} \mathrm{~S}^{\mathrm{a}}$ de Tourega, Evora - Gorges PS 26: villa, contrapeso de prensa-; Santa Vitoria do Amiexial - Gorges PS 28: importante villa, prensas-; Abicada, Mexilhoeira Grande (Portimao) — Gorges PS 38: prensas y cuvas-; Quinta do Marim, Olhao -Gorges PS 39: cella vinaria (u olearia)-.

Al margen, pues, de las áreas de concentración de la costa catalana y del Valle del Guadalquivir, son pocos los ejemplos claramente aducibles.

\section{ALMACENES}

Otro elemento interesante desde el punto de vista económico es la presencia de almacenes, como estancias y como conclusión lógica de la acumulación de dolia y ánforas, en ciertos establecimientos en los que se puede trascender de la simple presencia de envases o fragmentos cerámicos.

- Cataluña:

Els Ametllers, Tossa de Mar -Gorges GE 26, Horreum, dolia y ánforas (la villa se dedica en su primera fase, desde fines del s. I. d. C. a la producción de vino y aceite, además de salazones), San Cugat, Mataró Gorges B 53, cinco silos romanos esféricos, dolia, fragmentos de ánforas-, Ermita de S. Martín de la Mata, Mataró - Gorges B 55, tres silos romanos, dolia-, Rectoría, Pachs - Gorges B 69, antigua estancia con mosaico se usa de almacén para dolia después de las invasiones del siglo III, se horadan los mosaicos para asentar los dolia-, Arrahona o La Salud, Sabadell -Gorges B 77, almacén con 68 dolia de 1'30 m. de diámetro y 1-1'50 de altura; propiedad imperial según Gorges-, Can Feu, Sabadell -Gorges B 80, muchas ánforas Dressel 1 A, Beltrán I, Beltrán III y Pascual 1 de fabricación local ¿actividad comercial con Italia y Bética, producción de vino local = Pascual 1?-, Casalot d'Espuny, Villafranca del Panadés -Gorges B 136, dos silos-, Can Pi i Gibert - Prevosti p. 140, ánforas alineadas-, Can Turó d'En Seriol -Prevosti p. 177, dos depósitos de opus testaceum comunicados-, Can Sentromà -Prevosti, p. 193, silos en el nivel anterior al 100-120 d. C.; dolia después, hasta mediados del siglo II; desde la $2^{2}$ mitad del siglo II, nave de almacenamiento ${ }^{32}$-,

\footnotetext{
${ }_{32}$ Véase: Gurt, J. M., y Ferrando, F.: “La villa de Sent-romá (Tiana) i el conreu de la vinya». Actes l colloqui d'arqueologia romana. El vi a l'antiguitat. págs. 189-198.
} 
Can Teixidor - Prevosti p. 234, dolium grande en una estancia-, Els Vilans, Aytona (Lérida) - Gorges L 21, numerosos dolia ( 1'5 m. de altura) y restos de ánforas tardías, Hostal Nou, Balaguer - Gorges L 26, aparición de una bodega subterránea con numerosos dolia, 23 in situ, y 10 sitios para otros tantos, no se sabe su destino: ¿trigo, aceite, vino?-, Centcelles, Constantí - Gorges T 18, almacén con dolia en el nivel de inicio del establecimiento, s. I.-, Vilardida - Gorges T 52, restos de silos medio llenos- Recordemos también entre las anteriores el grupo de establecimientos pertenecientes al ager de Barcino: los de Santa Madrona del Palau; Can Presses del Riu, Ca l'Espluga, St. Vicenç dels Horts, , S. Boi, Nta Sra de Sales (Viladecans i Gavà), Can Tintorer, Plaça de les Bruixes y Ca la Cordia (Molins de Rei), Pla del Vent (S. Joan Despí), todas ellas situadas en el Bajo Llobregat y de las que, como habíamos indicado, se descubrieron instalaciones industriales: prensas y almacenes destinados a la producción de vino, que conforman un elemento sumamente valioso.

- Levante: podemos citar:

Benaguacil - Gorges V 07, anforas y dolia para vino, está en zona vinícola-.

- Andalucía:

Cerro de las Vacas, Lebrija - Gorges SE 121, dolia, anforas vinarias Haltern 70, embarcadero-; El Conejil, Lebrija -Gorges SE 128, restos de ánforas Dressel 1C icomercio de vino?-; Cortijo de las Cercadas, La Campana —Ponsich II, p. 27, no 9: dolia y ánforas Dressel 20 (s. IV)—; Marchante, Lora del Río - Ponsich II, p. 51-4, no 93: depósito de ánforas, dependiendo de una granja vecina-; Paulenca, Guadix - Gorges GR 05, caso raro de parte rústica excavada, perteneciente al s. IV, con cocinas y almacenes para envases alineados-; Encinajero de los Frailes, Villarrubia - Gorges CO 016, almacenes con dolia, muelle de embarque sobre el río-; Manguarra y San José, Cartama (s. IV) ${ }^{33}$.

- Centro y Norte de España: Hay algunos ejemplos dispersos:

- Navarra:

Ermita de San Esteban, Falces - Gorges NA 9, parte rústica excavada, destino agrícola, complejo vinícola del siglo IV, con prensa bien conservada ( $\left.2^{\mathrm{a}} \mathrm{mitad}\right)$ - Funes - Gorges NA 10, depósito vinícola, bodega con cuatro salas con prensa y cubas y cuatro aún mayores para pisar las

3 Vid: E. Serrano, A. de Luque Moraño. «La villa de Manguarra y San José, Cártama (Málaga)». Segovia y la arqueología romana. pág. 372. 
uvas-, Liédena - Gorges NA 12, dolia de vino en una bodega-, Ermita de San Pedro, Villafranca - Gorges NA 22, dolia en un almacén de la primera fase de la villa, recubiertos por un mosaico posterior del s. III.

- Extremadura: La Cocosa: dependencias con dolia para almacenar aceite.

- Aragón: Chiprana, Dehesa de Baños - Gorges Z 10, yacimiento al borde del Ebro con posible muelle de embarque-.

- Soria: Merdancho, Garray -Gorges SO 17, horno de pan, cocina, establo y almacenes-.

- Galicia: Parada de Outeiro da Limia - Gorges OR 10, cincuenta recipientes empotrados en el suelo de dos en dos y dispuestos en círculos, para conservar granos.

- Norte de Portugal:

Tralhariz, Carrazeda de Anciaes - Gorges PN 03: la cantidad fragmentos de ánforas y dolia, teñidas de una materia orgánica que puede ser vino, muestra que se trata de una bodega-; Canelas do Douro Gorges PN 15: cella vinaria, dolia con restos fosilizados de aceite-;

\section{- Sur de Portugal:}

Santa Vitória do Ameixial -Gorges PS 28: importante villa, silos-; Quinta do Marim, Olhão - Gorges PS 39: cella vinaria (u olearia), con tres dolia encastrados en el pavimento-.

\section{MATERIAL AGRÍCOLA}

Los hallazgos de material agrícola especialmente de instrumental empleado para las labores del campo o tareas dentro de la explotación vinculadas al cultivo o al cuidado del ganado son muy escasos. Ello se debe a la escasa exploración de las partes rústicas de los establecimientos, pero también a la corrosión de los materiales de que muchos estaban hechos, especialmente del hierro y la madera. Pero no incluiremos únicamente la mención de aperos donde se hayan encontrado, sino también la de molinos de trigo y piezas de industrias domésticas como telares, parte de una actividad económica autárquica agraria. Todos estos hallazgos mencionados son relativamente comunes sólo en establecimientos del centro y norte de la Península, como se aprecia en su distribución geográfica:

- Navarra:

Falces -Gorges NA 9: hallazgo de numerosos aperos; hoces, láminas de cuchillos etc.- 
- Andalucía: Sevilla:

Cortijo de los Olivos -Ponsich p. 231, no 23: establecimiento entre cuyos restos se conserva una gran muela de molino de grano-.

- Extremadura:

La Cocosa, con hallazgo de aperos de hierro.

- Soria:

El Palomar, Matalebreras, - -Gorges SO 21: muelas de molino ¿trigo?-; Merdancho, Garray - Gorges SO 17, horno de pan, cocina, establo y almacenes-; Los Quintanares, Rioseco - almacenes (dolia) ${ }^{34}$.

- Norte de Portugal:

Tralhariz, Carrazeda de Ansiaes -Gorges PN 03: muelas, pesas de telar-; Alhadas de Baixo, Coimbra - Gorges PN 04: pesas de telar, fragmentos de muela-; Montemor o Velho, Coimbra - Gorges PN 07: pesas de telar-; Longroiva, Guarda - Gorges PN 08: fragmentos de molinos de mano-; Póvoa de Mileu, Guarda — Gorges PN 09: una muela, pesas y lanzaderas de telar-; Vilarinho das Paranheiras, Chaves - Gorges PN 19: instrumentos agrícolas sin especificar-.

- Centro de Portugal:

Ferro, Castelo Branco - Gorges PC 01: muela de molino de mano-; Arnal, Leiria -Gorges PC 06: muelas de molino manual-; Belver, Portâlegre -Gorges PC 14, molinos de mano--; Póvoa de Meadas, distrito de Portalegre - Gorges PC 22: pesas de telar-.

\section{INSTALACIONES MINERAS, INDUSTRIALES Y PESQUERAS}

Los vestigios de actividades mineras, pesqueras e industriales nos permitirán clasificar cierto número de villae en las que se realizan actividades extractivas y de transformación no vinculadas, como la fabricación de ánforas, al conjunto de la producción agrícola. Así, dentro de esta categoría podemos enumerar:

a) Villae maritimo pesqueras:

Se caracterizan porque además de estar situadas en la línea de costa muestran claros signos de haber sido albergue de actividades de

${ }^{34} \mathrm{~T}$. ORTEGo refiere el hallazgo de diversos restos de instrumental agrícola y artesanal sin especificar. V.: «La villa romana de "Los Quintanales" en el término de Rioseco (Soria)". Segovia y la Arqueología Romana. pág. 290. 
transformación de la pesca; la fabricación de salazones o de garum. Los establecimientos que a continuación enumeramos son ejemplo de esas actividades, aunque no en todos ellos tenemos la certeza de que se trate de villae.

\section{- Cataluña, Levante y SE:}

Els Ametllers, Tossa de Mar-Gorges GE 26: como indicamos anteriormente la villa se dedica en su primera fase, desde fines del s. I. d. C. a la producción de vino y aceite, además de salazones-; Baños de la Reina, Calpe -Gorges A 02: villa próxima a un establecimiento de salazones, con cubas y salina, era agrícola y marítima-; Los Nietos - Gorges MU 42: villa marinera de salazones, fabricación de garum, con tres estanques-.

\section{- Costa Sur peninsular:}

Almuñecar - Gorges GR 01: villa del Bajo Imperio, con estanques y viveros para piscicultura-; Rio Verde, Marbella — Gorges MA 08, villa que tenía fábrica de púrpura (depósito de murex) o de ¿garum?-; Las Torres, S. Pedro de Alcántara - Gorges MA 10: villa pesquera ¿garum?, restos de piscinas, vértebras de atún, ancla de plomo-: El Faro, Torrox —Gorges MA 13: villa industrial, piscinas de salazón, puerto--; Boca de Río, Budens (cerca de Lagos, Algarve) - Gorges PS 34: villa con instalaciones de salazón-; Abicada, Mexilhoeira Grande (Portimao) —Gorges PS 38: posible instalación de industrial de garum en el Bajo Imperio-; Cerro da Vila, Quarteira - Gorges PS 41: villa agrícola (embalse próximo), con establecimiento de garum anexo-.

- Costa Occidental Peninsular:

Panxón - Gorges PO 03: quizás villa pesquera, vestigios de antiguo puerto, epoca tardía: s. III-IV-; Alto de Martim Vaz, Povoa de Varzim Gorges PN 12: villa marítima dedicada a conservas de peces: garum o salazón-; O Fontao, Lavra, distrito de Porto - Gorges PN 12: pesca y trasformación en garum o salazón (cuencas excavadas en la roca en la playa, s. II-IV d. C.)-.

b) Villae mineras:

Podemos citar a través de la península: En Andalucía, una serie de sitios prospectados por Ponsich en Peñaflor en la provincia de Córdoba al borde del río Guadalquivir y que muestran una actividad en la minería del hierro, y del cobre, aunque no están reconocidas como villae ${ }^{35}$. Leoncillo,

${ }_{35}$ V.: Ponsich, M.: Implantation Rurale II, págs. 103-106, 108. 
Villar del Rey - Gorges BA 32, escorias que pueden proceder de alguna explotación minera próxima-, Salinas de Rosio - BU 40, villa romana en relación con minas de sal próximas-, Vega de Soldán, Sta Columba de Somoza - Gorges LE 11, al pie de Las Médulas, ligada a la explotación del oro en el Monte Teleno, a la vez que dominaba la fértil vega de Soldán; función agrícola y ¿administrativa? ¿procurador de las minas?-, Monasterio de Castro Dozón, Dozón - PO 01, nacería en relación con la explotación minera (siglo I d. C.)-, Outeiro, Rodeiro - PO 04, nacería en relación con la minería en el siglo I d. C., con dos niveles, uno del siglo II d. C. y otro de fines del III-, A Lanzada, Sanxenxo - Gorges PO 05, sobre un antiguo castro, villa con dos niveles quizás relacionable con minas próximas de caolín y estaño-.

c) Villae industriales:

Es ésta una clasificación problemática, pues los ejemplos que enumeraremos no se caracterizan por que la industria fuese su razón de ser, sino porque tenemos el testimonio de que se desarrollaron esas actividades en sus dependencias, dentro de la autarquía de la explotación. Así: Canelas do Douro - Gorges PN 15: talleres para el trabajo de metales (escorias de hierro y de cobre)-; Póvoa de Cós, Alcobaça -Gorges PC 08: villa (comienzo en el s. I a. C.) con horno para tratar hierro en su inmediaciones-; Herdade das Barrosas, Serpa - Gorges PS 20: villa o poblado, escorias de hierro-; En Andalucía Ponsich señala la presencia de posibles instalaciónes de fabricación de instrumentos agrícolas, en el término de Guadalcázar usando los metales de Sierra Morena ${ }^{36}$; también en el término de La Rambla, Córdoba señala un ejemplo de villa con actividad metalúrgica ${ }^{37}$, en La Carlota ${ }^{38}$ y en Fuente Palmera ${ }^{39}$. En Cataluña: Ca l'Alemany -Prevosti, p. 86, interesante porque se encontraron escorias de hierro, hallazgo que en Cataluña solo se dio en otro estudiado por Serra Ràfols, PLAV, 5, 1968, p. 9-21-, Can Trencalòs -Prevosti, p. 176: la villa poseía estancias dedicadas a la actividad industrial que la autora cree pueda haber sido la fabricación de hierro o algo semejante-,

36 Ponsich M.: Implantation rurale, II, pág. 205, n. ${ }^{\circ} 113$ : Cortijo de Reynilla, y n. ${ }^{\circ} 114$ : Rabanitos, una villa con una pequeña industria metalúrgica de hierro y posible fábrica de instrumentos agrícolas, ambos cerca de Guadalcázar.

37 Cortijo del Ochavillo, villa con escorias de hierro (restos de fundición), ocupada en el s. IV. Ponsich: Implantation rurale II, pág. 213, n. ${ }^{\circ} 155$.

ss Cortijo de Cortejillo; restos de establecimiento y escorias de hierro, s. IV. Ponsich: Implantation rurale, II, pág. 214, n. ${ }^{\circ} 162$.

${ }_{39}$ La Herrería: posible villa antigua que fabricase sus instrumentos metalúrgicos con los productos de Sierra Morena. Restos de escorias de plomo. V.: Implantation rurale, II, pág. 224, n. ${ }^{\circ} 226$. 
También Can LLauder - Gorges B 52, con hornos para vidrio-. Un caso particular es, en este contexto: Montiho das Laranjeiras, Alcoutim -Gorges PS 31: hallazgo de grandes cantidades de mangos de husos de metal, pesas y lanzaderas de telar que hacen pensar en una industria textil.

Actividades en este marco pueden atestiguarse de manera muy dispersa y en establecimientos que fabrican para su uso materiales como vidrio, o fundición de hierro.

\section{EMBARCADEROS}

Señalemos, por último, por lo significativo que es de un contacto con el exterior, y la orientacion comercial que puedan sustentar, la existencia de embarcaderos reiacionables con villae en el Valle del Guadalquivir. En esta región, favorecida por las condiciones de navegabilidad del río, se multiplicaban los puntos de embarque de aceite y otros productos, como Cerro de las Vacas, Lebrija — Gorges SE 121-; Matahijas, Guillena Ponsich p. 83, no 63-, o Encinajero de los Frailes, Villarrubia - Gorges CO 16-, cuyo tráfico organizarían una serie de puertos como Oducia, o llipa. Pero también podemos apreciar restos de instalaciones portuarias privadas en algunos establecimientos de la costa mediterránea y en el Valle del Ebro. Así, en Dehesa de los Baños, Chiprana - Gorges Z 10-, se informa de un posible embarcadero al borde del Ebro, igualmente villas costeras y dedicadas a la pesca o salazones podían poseer sus propias instalaciones portuarias, como El Faro, Torrox - Gorges MA 13-0 Panxón - Gorges PO 03-.

A partir de los hallazgos que acabamos de describir, y que tienen forzosamente un alcance provisional, la tarea de obtener datos sobre la dedicación de las villae conocidas a través de los signos que antes citamos, es el paso siguiente que debemos dar, y se presenta dificultosa por el escaso conocimiento que, como se acaba de ver, poseemos de la mayor parte de los establecimientos rurales de la península que no estén situados en la franja levantina, Bética y, en menor grado, Valle del Ebro. Los datos que podemos utilizar pueden ser analizados en una perspectiva regional, con atención en las siguientes áreas peninsulares: El Nordeste, el Valle del Guadalquivir, la región de Mérida, la Meseta y el Noroeste. En esas regiones encontraremos establecimientos que nos marquen la pauta de lo que caracterizaba la economía agraria de cada una de ellas y podremos además intentar poner en relación las de algunas con las de áreas situadas fuera de la península, pero próximas, como la Narbonense. 
La producción de una serie de cultivos llamados a ser exportados hacia Italia o las fronteras, marcará la dirección de la exploración a realizar en los establecimientos rurales de aquellas regiones en las que se dan a la vez las condiciones de situación costera o situación cerca de vías fluviales navegables, hinterland fértil y propicio para cultivos especializados, precoz implantación rural romana, y, por tanto romanización profunda. En estos casos se dan las condiciones para que la explotación del campo dé lugar a una orientación parcialmente comercial, dentro de las limitaciones que antes señalamos, y, sobre todo, dentro del patrón de circulación de bienes vigente, en el que no podemos sobrevalorar el comercio libre. En cambio, en las regiones en las que la facilidad de comunicación acuática no es posible, creemos inútil suponer la existencia de agricultura de exportación, y la acumulación de excedentes habría que comprenderla en el marco de la lógica expresión de riqueza de los propietarios, de sus necesidades personales y sociales, también, en una relativamente limitada forma, el aprovisionamiento de los núcleos urbanos, que en ningún caso alcanzaron más que la dimensión de ciudades medianas, o el del ejército de ocupación en los territorios del Norte peninsular.

Con todos esos condicionantes; es evidente, que en la franja levantina y en la Bética los relativamente abundantes datos de que disponemos confirman, por una parte, la vigencia en esas áreas de una estructura económica y una organización de la actividad agraria que, desde fines de la República, muestra un evidente parentesco con las de Italia. Esta proximidad es el producto de varios factores: las condiciones climáticas mediterráneas, la relativamente alta evolución que en los tiempos prerromanos se había alcanzado ya en la economía de los pueblos indígenas -especialmente en el Valle del Guadalquivir, y la presencia e influencia de un elemento itálico, que sobre todo en el NE y Valle del Ebro, sin duda como veteranos tras su servicio en la península, se fijó en un número creciente a lo largo del proceso de conquista, y que puede haberse beneficiado de una política colonial de Roma en determinados momentos (Itálica, Valentia, Palma). Sin embargo no hay base sólidas para creer en la multiplicación de episodios de este tipo, como los que supuestamente darían lugar a núcleos catalanes como Baetulo o lluro ${ }^{40}$. No creemos en la

40 Somos escépticos ante la hipotética existencia de una colonización mariana en la Peninsula, aunque J. GuItART: Baetulo. Topografia arqueológica, urbanismo e historia. Badalona, 1976, pág. 239 y ss., "La Laietània: el context històric-rqueològic com a marc interpretatiu de la producció y comerç del vi a la regió". Acte I colloqui d'arqueologia romana. El vi a l'antiguitat. págs. 146-7, o M. Prevosti: Cronologia i poblament a làrea rural de Baetulo. Passim, la postulen para explicar el nacimiento de Badalona y otros núcleos próximos. 
existencia de una política coherente por parte de Roma que patrocine o favorezca estos procesos antes de mediados del siglo I a. C.

La convergencia de los tres factores citados explica que ya en la época augústea sean tan numerosas las huellas de actividad económica, a través de talleres de ánforas como las Pascual 1 y, más tarde las Dressel 2-4, en Cataluña especialmente, que son el signo de la existencia de una próspera agricultura en la que la producción de vino a gran escala juega un importante papel, mientras que en el Sur, el aceite parece ser el motor de unas actividades parecidas, siendo la fabricación de ánforas Dressel 20 el signo de esta abundancia de producción.

Las informaciones antes reseñadas, aunque son modificadas constantemente por el proceso de exploración arqueológica, nos ofrecen, como indicamos, un panorama bastante indicativo de las diferentes estructuras económicas de las áreas más romanizadas de la península en contraste con la Hispania interior y septentrional, aunque el patrón de explotación que se extiende por ambas tenga las mismas características. Pero si bien la villa es el modelo de referencia universal para organizar la economía agraria, la configuración que ésta tendrá en las diferentes áreas variará. Las diferentes fórmulas de explotación tiene, sin embargo en común, la orientación autosuficiente de las villae, que buscan erigirse en un circuito autárquico en el plano agrícola, obteniendo todos los productos dentro de sus propias tierras, y extendiendo en lo posible esta autosuficiente a algunas necesidades artesanales, como la fabricación de materiales de construcción o la de envases para almacenar productos (dolia, ánforas) ${ }^{41}$. En las áreas más favorecidas: el valle del Guadalquivir y la costa catalana y levantina, las circunstancias derivadas de sus posibilidades productivas, de su posición geográfica y de su vinculación temprana con Roma permitirían,

${ }^{41}$ Es un problema complejo establecer la relación entre propietarios y marcas de ánforas; para Andalucía la presencia de una concentración de la fabricación de ánforas en lugares como Puerto el Barco, Brenes en un área próxima a Sevilla, o La Catria en Lora del Río, es innegable, quedando abierta la cuestión de si las marcas corresponden a los mayores propietarios. $\mathrm{V}$.: PoNsICH: Implantation rurale. págs. 70-71. La solución más defendida es la que R. Etienne: «Les problemes historiques du latifundium». $M C V$, VIII, 1972, pág. 625, J. Remesal: "La economía oleícola bética: nuevas formas de análisis". A. Esp. Arq. 1977, pág. 91, y M. Prevosti: «El taller de ánforas de Torre Llauder: nuevas aportaciones". Actes i colloqui d'arqueologia. El vi a l'antiguitat, págs. 203-4 exponen vinculando las marcas de ánforas con los propietarios del producto aunque la producción de esas ánforas se concentre en unas pocas explotaciones que abastecen a las demás y que se sitúan precisamente en los puntos de expedición del producto, puertos de embarque, o vías de salida hacia el mar. La cuestión ha sido tratada recientemente por $F$. Mayet: «Les figlinae dans les marques d'amphores Dressel 20 de Bétique». REA LXXXVIII, 1986, págs. 285-305 y F. Jacques: "Un exemple de concentration foncière en Bétique d'apres le témoignage des timbres amphoriques d'une famille clarissime». MEFRA 102, 1990, 2, págs. 86-899. 
śin embargo, que esta autosuficiencia de las villae diese lugar a la explotación de ciertos cultivos para obtener un excedente susceptible de exportación, sea a través del comercio libre, sea a través de mecanismos de abastecimiento interno, o bien a través de requerimientos cuyo origen era el abastecimiento de Roma o el ejército. Creemos que las tres formas de circulación jugaron su papel aunque sea difícil precisar el lugar y la importancia concreta de cada una de ellas.

Los datos que enumeramos anteriormente nos permiten descubrir qué tipo de producciones predominantes eran cosechadas en las tierras de las que eran centro. Como hemos visto la información que poseemos privilegia la áreas más meridionales y orientales de la península, en las que el clima y la orientación mediterránea facilitó el progreso de una agricultura especializada que parece desarrollarse según perfiles parecidos a la italiana, consecuencia de que existe una base social romanizada muy similar, y unos estímulos que operan de manera idéntica para primar ciertas producciones de prestigio y susceptibles además de incrementar los ingresos de los propietarios. Pero además en ese desarrollo de ciertos cultivos la importancia del control estatal, que en el caso del aceite resulta evidente ante la presencia documentada de funcionarios imperiales, juega también su papel, igual que la extensión de la propiedad de titularidad imperial, que desde Tiberio se hizo notoria y que vio un nuevo impulso con las confiscaciones realizadas por Septimio Severo.

El análisis de los hornos de alfares, y de las instalaciones vinarias o aceiteras conocidas en los establecimientos peninsulares muestra una logica concentración de hallazgos en las áreas geográficamente más dotadas por clima y suelo, circunstancias a las que se añaden la facilidad de la comunicación por mar o rio navegable para la circulación de los excedentes de la producción. En relación con ello está la concentración de los talleres de ánforas que, sobre todo en las provincias de Sevilla y Córdoba, a lo largo del Guadalquivir, no tiene equivalencia en el resto de Andalucia, y la densidad de alfares que tenemos en un lugar como Villar de BrenesPuerto el Barco, que parecen fabricar ánforas Dressel 20 para las aceiterías de la región de Alcalá del Río ${ }^{42}$, o La Catria, nos sitúa ante la realidad de una producción a gran escala que nos enfrenta al dilema de si la producción estaba vinculada a las villae o si se trata de industrias autónomas que laboren para una región extensa. A este respecto no deja ser significativo el hecho de que la marca que más ánforas produjo: VIRGIN,

42 V. PONSICH: Implantation rurale..., págs. 70-1. 
en Villar de Brenes-Puerto el Barco, parece corresponder con un propietario de tierras, el mayor de la comarca, atendiendo a su nivel de producción. Existiría en este caso integración entre la explotación agraria y la actividad industrial, según señala $M$. Ponsich ${ }^{43}$. En este sentido se pronuncia también M. a L. a Sánchez León, que señala la relación entre propietarios y propiedad en las estampillas de las ánforas aceiteras de la Bética y, en suma, que las marcas no están solo en relación con la distribución sinó también con la posesión y explotación de tierras, lo que implicaba normalmente poseer talleres propios ${ }^{44}$. Como señalaba ya $E$. Thevenot, las marcas corresponden a propietarios ricos, no a alfareros o intendentes de haciendas ${ }^{45}$.

Hay que tener en cuenta que la calidad de la arcilla necesaria para asegurar la solidez y estanqueidad de las ánforas hacía necesario instalar los hornos en los lugares en que se encontrase y donde el acceso fluvial fuese cómodo; por ello no podrían estar dispersos y formando parte de cada gran villa como los hornos de ladrillos o tejas. Siendo las ánforas el envase en el que la mayor parte del aceite era depositado y transportado, su fragilidad obligaba a eliminar el transporte terrestre, salvo excepciones muy localizadas. Por ello tenían tanta importancia la localización de los talleres al borde del río, donde podían ser llenadas y embarcadas sin riesgos. La relación entre ambos factores se ilumina más al comparar la concentración de talleres de ánforas a lo largo del Guadalquivir entre Sevilla y Córdoba y la ausencia de ellos en las tierras situadas más allá de esta ciudad. Ponsich, advirtiendo la diferencia, concluyó que las posibilidades de navegación del río explicarían la situación. En el triángulo Hispalis-Corduba-Astigi la navegación permitiría el uso de ánforas y dolia a gran escala para almacenar el aceite, mientras que aguas arriba de Córdoba la imposibilidad de navegar con regularidad obligaría a otros medios de envase y almacenamiento: los odres; en ellos sería transportado el aceite hasta

${ }_{43}$ PONSICH, R: Implantation rurale..., pág. 71.

${ }_{4}^{4}$ V.: M. ${ }^{2}$ L. ${ }^{a}$ SANCHEZ LEON: Economía de la Hispania Meridional durante la dinastía de los Antoninos. Salamanca, 1978, pág. 193 ss. La autora cita abundantes ejemplos de grandes propietarios agrarios con figlinae, o talleres de ánforas, y señala además la importancia creciente de la propiedad imperial en el siglo ॥ d. C. Ibidem, págs. 197-9. También: G. CHIC GARCIA: «El intervencionismo estatal en los campos de la producción y distribución durante la época de los Antoninos». MHA, III, 1979, pág. 126.

45 E. Thevenot: "Una familia de negociantes en aceites establecidos en la Baetica en el siglo ॥: Los Aelii Optati». A.E.A. XXV, 1952, págs. 225-231. También G. Chic: “El intervencionismo estatal en los campos de la producción y la distribución durante la época de los Antoninos». MHA, III, 1979, pág. 126, es de la misma opinión. 
ciertos portus sobre el río, en los que se trasvasaría a ánforas y dolia definitivamente ${ }^{46}$.

En la regíon catalana y valenciana, la situación difiere en cuanto a que las necesidades de almacenamiento y exportación del vino, su producto excedentario fundamental, no motivaron la necesidad de separar los centros de producción de ánforas de las propias villae, sino que, en general forman parte del complejo de la explotación, salvo en los puertos como Baetulo ${ }^{47}$. Lo que no tiene equivalente alguno es la concentración de los hornos a la orilla del Guadalquivir en grandes complejos industriales no integrados físicamente en las explotaciones rústicas y que son muestra de una exportación gran escala que debía suponer una producción mucho más amplia que la de los vinos de la Tarraconense, además de un interés mucho mayor de las autoridades imperiales en la regularidad del abastecimiento, lo que explica su intervención a través de agentes en la exportación del aceite y en la producción a través de las crecientes extensiones de propiedad imperial que las confiscaciones u otras vías irían colocando en sus manos desde los tiempos de Tiberio y, sobre todo, Septimio Severo.

Hay una continuidad en el paisaje agrario desde la época romana a la época actual, efectiva sobre todo en aquellos lugares en los que la introducción de nuevos cultivos no alteró la preeminencia de la tríada mediterránea típica; trigo, vid y olivo. Estos cultivos, en Cataluña, Levante y Sur, eran susceptibles de dar buenos rendimientos y esas posibilidades se fueron haciendo realidad, con el avance de la romanización, la estabilización política a la que se asiste tras las guerras civiles del siglo I a. C., y con la implantación de un patrón de ocupación del espacio rural similar al italiano con las villae como centro, consecuencia, en buena medida de la implantación de una población inmigrada que, si bién se venía instalando desde las primeras fases de la conquista, no alcanzó una importancia numérica sustancial hasta los grandes asentamientos realizados por César y Augusto. En esas áreas tenemos elementos suficientes para intentar reconstruir la estructura productiva de las explotaciones.

Las noticias que las fuentes nos trasmiten elogiando el vino de unas partes de la península y el aceite de otras encuentran confirmación en la

46 V.: R. Thouvenot: Essai sur la Betique, pág. 269; M. Ponsich: Implantation rurale sur le Bas-Guadalquivir III, págs. 12-16; Idem: "Le facteur geographique dans les moyens de transport de l'huile de Betique". Producción y comercio del aceite. Il congreso, págs. 106-8.

${ }_{47}$ Un ejemplo en: Puerta, C.: Rodríguez, M.: "Una industria urbana de producció de vi a Baetulo (Badalona)». Actes / Colloqui d'arqueologia romana. El vi a l'antiguitat, pág. 183-8. 
ya citada presencia de los restos numerosos de aceiterías en el valle del Guadalquivir, lugar del que se elogia en repetidas ocasiones ese producto, y de predominio de las instalaciones vinarias en la costa levantina y tarraconense. Este predominio de instalaciones para la elaboración de vino y aceite traduce la dedicación de las villae a una explotación, que no podemos calificar como monocultivo, pero que no por ello oculta una preferente dedicación por un cultivo especializado que desborda las necesidades de la autarquía de la explotación. En el plano agrario, en las regiones más representativas que conocemos: El Maresme y el Bajo Guadalquivir, la presencia de esos cultivos especializados determina las características de la economía, además de responder a una estructura de la propiedad concreta, caracterizada por la mediana propiedad; sobre todo en el área catalana en la que, la correspondencia entre el tamaño de la explotación ideal propugnada por Catón y los modulos teóricos resultantes de relacionar el número de villae conocidas con la extensión del territorio agricola de Baetulo e lluro, por ejemplo, es bastante significativa ${ }^{48}$. En el área andaluza el panorama parece más complejo y la existencia de grandes propiedades latifundiarias junto con formas de propiedad mediana puede haber sido más común, sobre todo a partir del siglo II d. C., momento en que parece advertirse un proceso de concentración que según $\mathrm{M}^{\underline{a}} \mathrm{~L}^{\underline{a}}$ Sánchez León se manifestaría en las confiscaciones de $\mathrm{S}$. Severo, cuyas víctimas eran destacados elementos de las oligarquías municipales y que afectan a grandes propiedades ${ }^{49}$.

Las concentración de talleres de ánforas en las áreas citadas y su práctica ausencia en las tierras del interior de la península es una evidente muestra de que la estructura de la explotación de esas villae es diferente; observamos el peso predominante de la autosuficiencia, favorecida por factores convergentes de tipo geográfico y económico. Se trata de tierras menos aptas para una agricultura acorde con los criterios mediterráneos, y en muchos casos el peso de una economía pastoral es la manifestación evidente de estas diferencias; pero, además, la inexistencia de comunicaciones acuáticas impedía prácticamente cualquier tipo de actividad agraria cuyo producto fuese destinado a ser transportado a largas distancias en cantidades apreciables. Pocos productos podían sustraerse a estos condicionantes y serían expresión de lujo o de exotismo, con escasa influencia en el conjunto de la economía. El radio de influencia máximo serían los

48 V.: M. Prevosti: Cronologia i poblament a l'area rural de Baetulo, págs. 278-82, 293.

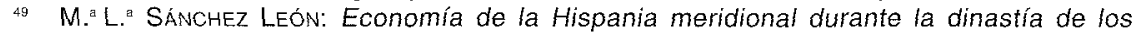
Antoninos. Salamanca, 1978, págs. 198-9 y 301-2. 
núcleos urbanos cercanos. De este modo, en el momento en que se edifican las villae, estas nacen con una vocación autosuficiente prácticamente absoluta, tal como ya Varrón señalaba que tendrían que ser en los casos en los que el aíslamiento fuese la característica fundamental de la explotación ${ }^{50}$. La presencia de núcleos urbanos poderosos es el único factor que alteraría este esquema, tal como debió ocurrir en el área de Mérida ${ }^{51}$. Pero en estas áreas las diferentes condiciones geográficas y la posible evolución de la ocupación rural romana favorece la concentración de grandes extensiones en manos de pocos grandes propietarios, al menos en algunas zonas, que disponen de explotaciones de dimensiones casi acordes con las que Columella contemplaba en su obra, o, incluso inmensos latifundios de mas de 5000 u $8000 \mathrm{Ha}$. No obstante la organización de las propiedades y el modo de explotación nada tiene que ver con los criterios establecidos por el autor ${ }^{52}$. En estas explotaciones una actividad agraria mixta, en la que los cultivos y el pastoreo coexistirian, y un diseño de las instalaciones con vistas a lograr la plena independencia del exterior, serían característica repetida. Los hallazgos de instalaciones agrícolas y de instrumental, o de almacenes debe ser entendido sirviendo esos intereses de sostenimiento de un circuito económico autónomo, al contrario que en la Bética o en las regiones de la Tarraconense productoras de aceite o vino.

La actividad agrícola, en cualquier caso, parece presente siempre en las villae; incluso en aquellas cuya finalidad primordial parece vinculada con actividades de tipo minero o industrial, la vertiente agrícola debió estar presente, como en Vega de Soldán, a fin de autoabastecerse de los

so R.R.I., 16, 4.

5i Lamentablemente, la prospección realizada por Ponsich en el Guadalquivir no tiene su equivalente en el territorio del Guadiana Medio correspondiente al territorio emeritense donde destacan únicamente los estudios de establecimientos concretos como La Cocosa, Satiago de Bencáliz, etc. Pero sólo La Cocosa y Los Términos fueron excavadas en su parte rústica y nos dan por ello indicaciones económicas, especialmente la primera. Ver: Luis Alonso Rubio Muñoz: "Un asentamiento rural en la cuenca media del Guadiana: La villa romana de Pesquero». Anas, I, 1988, págs. $72-3$, n. ${ }^{\circ} 44$.

52 J. C. GoRGEs: Les villas hispanoromaines, págs. 98-99 aprecia este panorama con formas latifundiarias extremas dominante en áreas correspondientes al sur de Portugal; $1500 \mathrm{Ha}$. en torno a Beja, y entre 3000 y $8000 \mathrm{Ha}$. en otras. No obstante J. DE ALARCAO: O dominio romano en Portugal. Mem Martins, 1988, pág. 108, señala lo precario de esos cálculos, crítica que se acentúa en: J. DE Alarcao et alii: Portugal. Das origens á romanizaçao en: J. SeRrao y A. H. DE OLIVEIRA Marques: Nova História de Portugal, vol. I, pág. 419, donde frente a esas desmesuradas dimensiones señala que la prospección sistemática de algunas áreas del Alentejo descubre un panorama diferente: villae que poseerían de 150 a $420 \mathrm{Ha}$., dejando lugar para pequeñas propiedades de circa $20 \mathrm{Ha}$. Con lo cual se descarta la idea de latifundio en época alto imperial en al menos parte de la región, a reserva de que en otras zonas, sí pueda haberse desarrollado la gran propiedad. 
alimentos necesarios. Carácter mixto deben haber tenido, incluso las villae marítimas en las que tuvo lugar la transformación en salazones y garum de la pesca.

Los restos de instalaciones de transformación y almacenamiento de productos agrícolas en las villae son un evidente testimonio de una actividad intensa que, en el plano evolutivo plantea algunos problemas, pues los materiales conocidos se concentran en unos momentos determinados; así, las instalaciones para la transformación del vino y las industrias de ánforas en la Tarraconense, ofrecen un perfil cronológico que se encuadra fundamentalmente entre la segunda mitad del siglo I a. C. y el final del siglo I d. C. o principios del siglo II. En la Bética la situación es parecida, es a los primeros siglos del Principado a la que corresponden la mayor parte de los materiales conocidos. En el interior de la península, en cambio, la abundancia de villae que alcanzaron su definitiva configuración en el siglo IV hace que los escasos ejemplos de instalaciones rústicas que podemos conocer se correspondan con fases tardías.

Es natural que la situación que acabamos de indicar pueda ser la base para intentar reconstruir la evolución de la estructura de producción agraria de las villae en relación con el lugar que la península puede haber jugado en el concierto mediterráneo. No obstante conviene no olvidar las advertencias que A. Tchernia lanza contra la tentación de basar esclusivamente en los datos conocidos la reconstrucción de tendencias o corrientes económicas; al insistir en la disparidad de informaciones que las fuentes y la arqueología proporcionan, llama la atención sobre la imposibilidad que la arqueología a veces tiene para aportar datos o confirmar los de otras fuentes ${ }^{53}$.

53 TCHERNIA: Le vin d'italie, págs. 292-294, señala que la dependencia del material anfórico para medir la importación de vino en Roma es engañosa porque sólo remite a un tipo de envase, aunque el conjunto del material correspondiente a ánforas vinarias de los siglos III y iv hallado en Roma, que disminuye ostensiblemente respecto a los siglos anteriores, es una buena base para postular la baja de la llegada de este producto de las provincias, lo cual tiene consecuencias para la reconstrucción de la evolución económica de la Península lbérica. Pero también muestra que en ocasiones la desaparición de un tipo de ánforas no tiene que ver con el final de una producción. lbidem, pág. 295. 